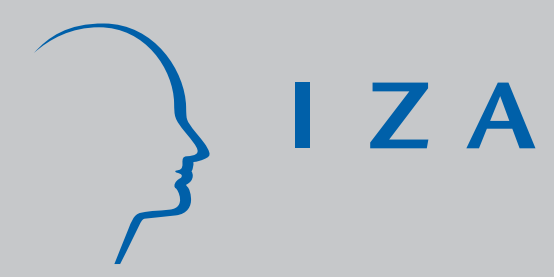

IZA DP No. 3892

\title{
An Assignment Model with Divorce and Remarriage
}

Pierre-Andre Chiappori

Murat lyigun

Yoram Weiss

December 2008 


\title{
An Assignment Model with Divorce and Remarriage
}

\author{
Pierre-Andre Chiappori \\ Columbia University \\ Murat Iyigun \\ University of Colorado, \\ CID at Harvard University and IZA
}

Yoram Weiss

Tel Aviv University and IZA

\section{Discussion Paper No. 3892 \\ December 2008}

\author{
IZA \\ P.O. Box 7240 \\ 53072 Bonn \\ Germany \\ Phone: +49-228-3894-0 \\ Fax: +49-228-3894-180 \\ E-mail: iza@iza.org
}

Any opinions expressed here are those of the author(s) and not those of IZA. Research published in this series may include views on policy, but the institute itself takes no institutional policy positions.

The Institute for the Study of Labor (IZA) in Bonn is a local and virtual international research center and a place of communication between science, politics and business. IZA is an independent nonprofit organization supported by Deutsche Post World Net. The center is associated with the University of Bonn and offers a stimulating research environment through its international network, workshops and conferences, data service, project support, research visits and doctoral program. IZA engages in (i) original and internationally competitive research in all fields of labor economics, (ii) development of policy concepts, and (iii) dissemination of research results and concepts to the interested public.

IZA Discussion Papers often represent preliminary work and are circulated to encourage discussion. Citation of such a paper should account for its provisional character. A revised version may be available directly from the author. 
IZA Discussion Paper No. 3892

December 2008

\section{ABSTRACT}

\section{An Assignment Model with Divorce and Remarriage*}

We develop a two-sided matching model with positive sorting, divorce and remarriage. Match quality for each couple is revealed ex post and those with poor draws divorce. Competition determines lifetime expected utilities but per-period utilities depend on the laws that govern the distribution of assets upon divorce. We discuss separately cases in which remarriage is or is not feasible and cases in which commitments are or are not made. In all cases, lifetime utilities are exactly pinned down by equilibrium (stability) requirements. Moreover, ex-post Nash bargaining and ex-ante commitment yield the same non-contingent intertemporal allocations. We then analyze the impact of changes in the property division upon divorce, considering for instance a reform that favors women. The short-term impact of the reform on the allocations of already married wives is positive. However, its long-term impact on yet unmarried women is not because such a reform generates lower utility for women within marriage which exactly offsets their higher prospective divorce settlement. When remarriage is possible, more complex effects could occur: the reform typically alters divorce probabilities and it may affect the total surplus generated by marriage, thus either increasing both spouses' welfare or decreasing both.

JEL Classification: $\quad \mathrm{J} 12, \mathrm{~J} 16, \mathrm{~J} 24$

Keywords: matching, intra-household allocations, Becker-Coase theorem

Corresponding author:

Pierre-Andre Chiappori

Economics Department

Columbia University

1009A International Affairs Building, MC 3308

420 West 118th Street

New York, NY 10027

USA

E-Mail: pc2167@columbia.edu

\footnotetext{
* We thank Robert Pollak for useful comments and suggestions as well as workshop participants at the 2008 SOLE Meetings, the University of Chicago, New York University, Cornell University and the University of Calgary. Pierre-Andre Chiappori gratefully acknowledges financial support by the NSF Economics award No: SES-05-32398 and Murat lyigun thanks NSF for Human and Social Dynamics Grant No: SES-0527751.
} 


\section{Introduction}

The spousal matching and assignment model has been an important workhorse of the literature on the economics of the family since the seminal contributions of Shapley and Shubik (1972) and Becker (1981). This model is applicable to the analysis of marriage patterns in a given isolated "marriage market" under static conditions. In particular, it can predict who marries whom and the division of marital gains between husbands and wives. ${ }^{1}$

In this paper, we propose a spousal matching model with divorce and remarriage that can be applied to modern marriage markets which are characterized by high turnover, whereby many individuals divorce and remarry (Browning et al., in progress, ch.1). Turnover is generated by introducing match-specific random shocks that are observed after marriage has taken place. In contrast to search models that impose frictions in the form of random meetings that are spaced over time (e.g., Mortensen, 1988), we maintain the competitive spirit of the assignment model by putting no restrictions on meetings. However, some non-competitive elements appear in our model too due to ex-post rents that arise when match quality is revealed.

The main ingredients of our model are as follows: There is a continuum of men and women who live for two periods. Each agent is characterized by a single attribute, income (or human capital), with continuous distributions of incomes on both sides of the marriage market, so that each agent has a close substitute. The economic gains from marriage arise from joint consumption of a public good and from a nonmonetary common factor that is match specific. This match quality for each couple is revealed ex post and those with poor matches may divorce. Finally, we rely on a 'Becker-Coase' framework, in the sense that utility is transferable both between spouses and after divorce.

For analytical purposes, we proceed in two steps: In the first part of the paper, we analyze a model in which remarriage is ruled out following divorce. Then, in the second part, we examine a more comprehensive model in which divorcees can rematch with others in the same cohort (who could either be never married or divorcees themselves). We assume throughout that a unilateral divorce law is in effect and that divorce laws determine the spousal distribution of incomes upon divorce. Therefore,

\footnotetext{
${ }^{1}$ In recent years, there have also been various efforts to unify these models with stages of the life cycle prior to marriage. Embedding a spousal assignment framework into a model of pre-marital investment is relevant to the extent that the educational attainment and labor supplies of men and women respond to not only the returns in the labor market, but also incentives in the markets for marriage. See, Iyigun and Walsh (2007) and Chiappori, Iyigun and Weiss (forthcoming).
} 
income distributions in the remarriage market and the first-marriage market may differ. We also assume that lending or borrowing is not an option. ${ }^{2}$ Because of public goods, spousal incomes complement each other, which can be shown to generate positive assortative matching according to income, even though divorce is endogenous. Finally, to avoid potential knife-edge outcomes, we assume that there are more women than men in the marriage market. ${ }^{3}$ As a consequence, we always have some unmarried women each period, though not necessarily the same women.

Extending the assignment model in such fashion enables us to distinguish between the expected lifetime utility of an agent and the inter-temporal pattern of per-period utilities. In a first marriage, before the match specific quality is realized, each individual has a very close substitute and competition fully determines the share that each person receives in marriage based on the anticipated outcomes following divorce. These shares are determined by two basic principles: (a) Due to competition from single women with slightly lower income but who are otherwise identical, married women in the lowest income classes cannot get any surplus in marriage (relative to being single), and (b) married spouses receive exactly their marginal contributions to marital surplus, or else they can be replaced by husbands or wives with slightly lower contributions. In the second period, after the quality of match is revealed, marriage continues if and only if the surplus of the marriage, including its non-monetary benefit, exceeds the sum of the outside options of the spouses, which depend on whether or not remarriage is possible.

However, if the marriage is of high quality and the partners wish to continue it, competition alone can no longer determine the shares within marriage during the second period. We consider here two possibilities: a Nash bargaining model in which people systematically renegotiate at the beginning of the second period, taking their second period outside opportunities as threat points. And an alternative framework which allows pre-commitment to second-period allocations. But in neither case can spouses commit not to divorce, which imposes some second-period individual rationality constraints. We show that, under the assumptions of our model, these two alternatives are equivalent. The simplifying assumption responsible for this result is

\footnotetext{
${ }^{2}$ Given the assumptions of fixed income and static conditions, the assumption of no borrowing or lending seems innocuous. However, when divorce is taken into account, issues such as who owns what and which married partner is responsible for family debts arise. As we shall show, divorce will affect the distribution of income and consumption over time even in the absence of any motive for saving or borrowing such as income growth or time preference.

${ }^{3}$ For reasons that we do not address, empirically it is true that women marry earlier than men. Hence, if there is some population growth, there will be excess number of women.
} 
the absence of spousal investments that can influence the quality of a match. This assumption is restrictive but allows us to pin down the assignments and lifetime expected payoffs when both divorce and remarriage are feasible.

We then utilize our framework to analyze how changes in divorce settlement laws might affect individuals' marriage patterns and the intra-marital allocation of resources. In particular, we consider a reform that increases the wives' share of household wealth after divorce. In the absence of remarriage opportunities, such a change in post-divorce property rights cannot affect divorce probabilities in our Becker-Coase world. However, it can influence the allocation of resources within a household, both before and after divorce - even among couples who do not eventually divorce.

We show that the short- and long-term consequences of the reform are different and generally opposite of one another. For couples already married, the reform can only improve the wives' welfare at the husbands' expense. While the exact scope of the reform depends on assumptions regarding commitment, either some or all women will strictly gain from the reform and no woman can lose (equivalently, no man can gain). Regarding couples who marry after the reform, the logic is quite different, because the new divorce settlement is taken into account at the matching stage, resulting in a different inter-temporal allocation of resources and welfare between spouses. Specifically, a change in divorce settlements aimed at favoring women typically generate offsetting intra-household transfers, eventually resulting in lower intra-marital allocations for all married women.

This basic insight remains valid when the option of remarriage is introduced. Again, among married couples women can only benefit from a reform increasing the wives' share after divorce; on the contrary, for couples who match after the reform, competition on the marriage market generates intra-household transfers that tend to offset its impact. However, many other aspects of the analysis change substantially because the income of agents in the remarriage market depends on the income of the ex-spouse whom they initially married. Thus, the whole income distribution shifts between the marriage and the remarriage markets, which can impact the assignment and prospective gains from divorce and remarriage. Consequently, redistributive policies are generally not neutral and can affect the expected surplus generated by (first period) marriages. This has several consequences. First, even in our transferable utility setting, divorce probabilities typically depend on divorce settlement laws. Second, the decision to get married or remain single could also be affected by these laws. For instance, if high-income men marry and are forced to pay a large transfer to their ex-wives upon divorce, they will enter the remarriage market with much less 
wealth than they had originally. But then some men may be better off by postponing marriage and entering the remarriage market at the top the (new) wealth distribution. Third and more fundamentally, the welfare consequences of changes in divorce settlement laws have the paradoxical property that they tend to increase or decrease the utility of both spouses simultaneously. The intuition is that any legislation that decreases the total surplus generated by marriage tends to harm both partners, after the adjustments implied by equilibrium. We actually provide a simple example in which a policy that raises the share of wives in family income upon divorce ends up reducing social welfare according to the Pareto criterion.

The ability of our simple model to generate explicit predictions regarding the impact of divorce laws on intra-family allocations is important for empirical work using collective models of the household. Such models can estimate a couple-specific sharing rule based on observed work and consumption patterns of married couples. Researchers have specified sharing rules that relate the shares of husbands and wives in the marital surplus to "distribution factors" such as sex ratios and divorce laws (Chiappori et al., 2002), welfare benefits (Rubacalva et al., 2008) and the legalization of abortion (Oreffice, 2007). This paper provides a theoretical underpinning for such rules, showing how an equilibrium analysis of the marriage market can theoretically restrict the form of the sharing rule and predict the impact of specific policy changes, thus opening the possibility of direct empirical tests.

\section{The Model}

\subsection{Preferences}

The economy is made up of individuals who live two periods. Individuals are characterized by their income, $y$ for men and $z$ for women. In each period, they derive utility from consumption of $n$ private goods, $q^{1}, \ldots q^{n}$ and $N$ public goods $Q^{1}, \ldots, Q^{N}$. Let $p^{1}, \ldots p^{n}$ and $P^{1}, \ldots, P^{N}$ denote the corresponding prices, with the normalization $p^{1}=1$. Married people also derive satisfaction from the quality of their match, $\theta$. The husbands' and wives' individual utilities take the form

$$
U_{i}=u_{i}\left(q_{i}, Q\right)+\theta, \quad i=h, w,
$$

where $q_{i}=\left(q_{i}^{1}, \ldots q_{i}^{n}\right)$ is the vector of private consumption of member $i, Q=\left(Q^{1}, \ldots, Q^{N}\right)$ is the vector of public consumption by the couple, and $\theta$ is the quality of the couplespecific match. We assume that preferences of married individuals are of the gener- 
alized quasi-linear (GQL) form (see Bergstrom, 1989).

$$
u_{i}\left(q_{i}, Q\right)=A(Q) q_{i}^{1}+B_{i}^{m}\left(Q, q_{i}^{-1}\right)+\theta
$$

where $Q=\left(Q^{1}, \ldots, Q^{N}\right)$ and $q_{i}^{-1}=\left(q_{i}^{2}, \ldots q_{i}^{n}\right)$. Here, $A$ and $B_{i}^{m}, i=h, w$, are positive, increasing, concave functions such that $A(0)=1$ and $B_{i}^{m}(0)=0$.

When single, preferences take the strictly quasi-linear form: ${ }^{4}$

$$
u_{i}^{s}\left(q_{i}, Q\right)=q_{i}^{1}+B_{i}^{s}\left(Q, q_{i}^{-1}\right)
$$

where again the $B_{i}^{s}, i=h, w$, are increasing concave functions, with $B_{i}^{s}(0)=0$. This utility is quasi-linear; in particular, the optimal consumptions of public goods and private goods other than good 1 are given by the conditions:

$$
\frac{\partial B_{i}^{s}\left(Q, q_{i}^{-1}\right)}{\partial Q^{j}}=P^{j}, \quad 1 \leq j \leq N \quad \text { and } \quad \frac{\partial B_{i}^{s}\left(Q, q_{i}^{-1}\right)}{\partial q_{i}^{k}}=p^{k}, \quad 2 \leq k \leq n .
$$

Neither these conditions nor the optimal levels of all private and public consumptions (except for good 1) depend on income. Let the latter be denoted $\left(\bar{Q}, \bar{q}_{i}^{-1}\right)=$ $\left(\bar{Q}^{1}, \ldots, \bar{Q}^{N}, \bar{q}_{i}^{2}, \ldots \bar{q}_{i}^{n}\right)$. To simplify notations, we choose units such that $B_{i}^{s}\left(\bar{Q}, \bar{q}_{i}^{-1}\right)=$ $\sum_{j=1}^{N} P^{j} \bar{Q}^{j}+\sum_{k=2}^{n} p^{k} \bar{q}_{i}^{k}, i=h, w$. Then, the indirect utility of a single person equals his or her income.

If a man with income $y$ is matched with a woman with income $z$, they can pool their incomes. Given $G Q L$ preferences, utility is transferable between spouses. There is a unique efficient level for the consumption of each of the public goods and each of the private goods 2 to $n$. Moreover, these levels depend only on the total income of the partners. The Pareto frontier is linear and given by

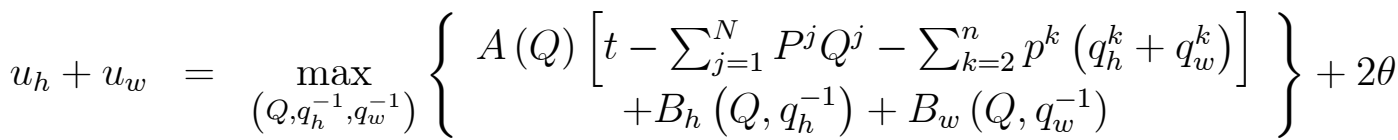

$$
\begin{aligned}
& \equiv \eta(t)+2 \theta \text {, }
\end{aligned}
$$

where $t \equiv y+z$ is the total family income while $u_{h}$ and $u_{w}$ are the attainable utility levels that can be implemented by the allocations of the private good $q^{1}$ between the two spouses, given the efficient consumption levels of all other goods. Assuming, as

\footnotetext{
${ }^{4}$ Both GQL preferences when married and quasi linear utilities when single are necessary to generate the Becker-Coase benchmark in which, in a static context, divorce laws do not affect divorce probabilities; see Clark (1999) and Chiappori, Iyigun, Weiss (2007).
} 
is standard, that the optimal public consumptions are such that $A(Q)$ is increasing in $Q$, we see that $\eta(t)$ is increasing and convex in $t .^{5}$

Due to the consumption of a public good, the two individual traits, $y$ and $z$ of a married couple, are complements within the household. This complementarity generates positive economic gains from marriage in the sense that the material output $\eta(t)$ the partners generate together exceeds the sum of the outputs that the partners can obtain separately. Specifically, the marital surplus $\eta(t)-t$ rises with the total income of the partners, $t$, and equality holds only when both partners have no income.

For any couple, match quality $\theta$ is drawn from a fixed distribution $\Phi$ with a mean $\bar{\theta} \geq 0$. Upon marriage, both spouses expect to derive the same non-monetary utility from marriage, $\bar{\theta}$. At the end of the first period, the match quality is revealed; a realized value of $\theta$ that is below the expected level $\bar{\theta}$ constitutes a negative surprise that may trigger divorce.

\subsection{Family Decisions and Commitment}

An important modeling issue is how families make decisions and in particular whether or not they can commit. In our model, the decision variables for a couple in each period are the amounts of the public good and the private good that the couple purchases and the division of the private good between them. At the beginning of each period, partners agree to buy the unique efficient level of the public good, namely that $Q$ which shifts the linear utility Pareto frontier outward as much as possible. There are no commitment issues involved here because (by construction) the levels of consumption within a period cannot be changed and each spouse can predict that, in the second period, $Q$ will be chosen at the unique and efficient level. ${ }^{6}$ Concerning the division of the private good, however, there is a conflict between the two partners and the question is how it is resolved. As we shall show, competition at the time of marriage fully determines the expected lifetime utility shares of the partners. The marriage market is cleared by a set reservation values of the expected lifetime utility that each agent requires to marry anyone of the opposite sex. Each agent marries the spouse that provides him or her with the highest surplus given these requirements

\footnotetext{
${ }^{5}$ By the envelope theorem, the derivative $\eta^{\prime}(t)$ is equal to $A(Q)$. Therefore, $\eta$ is increasing in $t$ and, if $A(Q)$ is increasing in $t$ as well, then $\eta$ is convex. Note that a sufficient (but by no means necessary) condition is that public consumptions are all normal.

${ }^{6}$ One could also imagine that partners play a non-cooperative contribution game that ends up with lower utility for both spouses. But given that the efficient level of $Q$ can be easily implemented simply by buying and consuming that quantity of the public good, such an assumption is hard to justify here.
} 
(see Browning et al., in progress, chapter 8). This outcome requires the possibility of bidding away potential spouses by offering them a larger amount of the private good within marriage. In the two period context discussed here, the share of the private good that each married spouse receives can vary across periods and the second-period division is anticipated when partners choose to marry. We shall consider here two cases: Either the next period allocation is determined by some known mechanism such as Nash Bargaining and the marriage market clears based only on the flexibility in the first-period allocations. Or alternatively, partners can sign binding contracts which determine allocations in both periods.

\section{$2.3 \quad$ Endowments}

There exists a continuum of men and a continuum of women. The measure of men is normalized to unity and the measure of women is denoted by $r$, where $r>1$. Each man receives an idiosyncratic income at the beginning of each period; their incomes, denoted $y$, are distributed over the support $[a, A], 0<a<A$, according to some distribution $F$. Similarly, each woman gets an income $z$ at the beginning of each period, and the $z$ 's are distributed over the support $[b, B], 0<b<B$ according to the distribution $G$.

Following divorce, there can be income transfers between the ex-spouses. We assume here that these transfers are fully determined by law and no further voluntary transfers are made. Specifically, if a man with income $y$ marries a woman with income $z$, her income following divorce is $z^{\prime}=\beta(y+z)$ and his income is $y^{\prime}=(1-\beta)(y+z)$. Note that the net income of a divorced person is generally different from what his or her income would have been had he or she not married. Therefore, marriage in the first period is associated with a potential cost (benefit) that depends on the identity of the prospective spouse. Consequently, the distribution of incomes among divorcees can differ from the distribution of income in the whole population.

Incomes in our model can be interpreted as either labor or property income. ${ }^{7}$ Redistribution corresponds to a legal approach where property incomes or spousal earnings are treated as a common resource and each spouse has some claim on the income of the other. The special case in which all incomes are considered private, implying no redistribution, is represented by a $\beta$ that is couple-specific, namely $\beta \equiv$ $\frac{z}{y+z}$.

\footnotetext{
${ }^{7}$ For simplicity, we do not allow savings or human capital investments during marriage so that both property and human capital are constant. Labor supply is also assumed fixed.
} 


\section{A Marriage Market Without Remarriage}

We begin our analysis assuming no "second hand" marriage market so that, following divorce, a person remains single for the rest of his or her life. In the first period, all men and women wish to marry because the expected economic and non-monetary gains from marriage are positive. However, because $r>1$, some women will have to remain single.

As usual, we solve the model backwards, starting with the divorce decision.

\subsection{Stable Matches and Lifetime Utilities}

\subsubsection{Divorce}

At the end of the first period, the true value of match quality is revealed and each partner of a couple $(y, z)$ can decide whether or not to stay in the marriage, based on the realization of $\theta$. Because utility is transferable within marriage and upon divorce, the Becker-Coase theorem applies and divorce occurs whenever the total surplus generated outside the relationship is larger than what can be achieved within it. ${ }^{8}$ Denoting total income of the partners by $t=y+z$, divorce occurs whenever

$$
\eta(t)+2 \theta<t,
$$

or, equivalently,

$$
\eta(t)+2 \theta<t \Leftrightarrow \theta<\hat{\theta}(t)=-\frac{1}{2}[\eta(t)-t] .
$$

In words, a marriage dissolves if the sum of the outside options, here $t$, exceeds $\eta(t)+2 \theta$, implying that reservation utilities are outside the Pareto frontier if the marriage continues.

On this basis, the ex-ante probability of divorce for a couple with endowments of $y$ and $z$ is

$$
\alpha(t) \equiv \Phi[\hat{\theta}(t)] .
$$

Note that the threshold $\hat{\theta}(t)$ rises with the income of the couple, $t$, and consequently the probability of divorce $\alpha(t)$ declines. Because of the complementarity of individual incomes in the household production process, the economic loss generated by divorce is higher for wealthier couples.

\footnotetext{
${ }^{8}$ See Clark (1999) and Chiappori, Iyigun and Weiss (2007) for detailed investigations of the transferability in the presence of public goods.
} 
The expected marital output (i.e. sum of utilities) generated over the two periods of a married couple with incomes $y$ for the husband and $z$ for the wife is

$$
S(t)=\eta(t)+2 \bar{\theta}+[1-\alpha(t)]\{\eta(t)+2 E[\theta \mid \theta \geq \hat{\theta}(t)]\}+\alpha(t) t .
$$

Note, first, that $S(t)>2 t$, because $\eta(t) \geq t$ and $E[\theta \mid \theta \geq \hat{\theta}(t)]>\bar{\theta} \geq 0$. Hence, all individuals prefer to get married rather than stay single. Secondly, $S(t)$ is increasing in $t$, hence in each partner's income. In particular, whenever women strictly outnumber men so that $r>1$, women belonging to the bottom part of the female income distribution remain single. Finally, individuals will sort positively into marriage. Indeed, since the marriage surplus only depends on total income $t$, the cross partial $\partial^{2} S / \partial y \partial z$ is equal to $S^{\prime \prime}(t)$. One can readily prove that $S(t)$ is convex and therefore that the traits of the two partners are complements even after the risk of divorce is taken into account (see Appendix) .

\subsubsection{Matching}

Who Marries Whom? Given the results of transferable utility and the complementarity of individual incomes in generating marital surplus, a stable assignment must be characterized by positive assortative matching. That is, if a man with an endowment $y$ is married to a woman with an endowment $z$, then the mass of men with endowments above $y$ must exactly equal the mass of women with endowments above $z$. This implies the following marriage market clearing condition:

$$
1-F(y)=r[1-G(z)]
$$

As a result, we have the following, spousal matching functions:

$$
y=F^{-1}[1-r(1-G(z))] \equiv \phi(z)
$$

or equivalently:

$$
z=G^{-1}\left[1-\frac{1}{r}(1-F(y))\right] \equiv \psi(y) .
$$

For $r>1$, all men are married and women with incomes below $z_{0}=G^{-1}(1-1 / r)$ remain single. Women with incomes exceeding $z_{0}$ are then assigned to men according to $\psi(y)$ which indicates positive assortative matching.

Positive assortative matching has immediate implications for the analysis of divorce. Because divorce is less likely when a couple has higher total income and 
individuals sort into marriage based on income, individuals with higher income are less likely to divorce. ${ }^{9}$

The Linear Shift $(\boldsymbol{L S})$ case A simple illustration of these results obtains under the assumption that the income distribution of women can be derived from that of men by a linear change in variables such that

$$
G(z)=F(\lambda z+\delta)
$$

for some fixed $\lambda$ and $\delta$. This is the case, for instance, when both distributions are lognormal for $y \geq a$ and $z \geq b$ with mean and variance $\left(\mu_{m}, \sigma_{m}\right)$ for men and $\left(\mu_{f}, \sigma_{f}\right)$ for women, if we assume that $\sigma_{m}=\sigma_{f}$. Then, $\lambda=\exp \left(\mu_{m}-\mu_{f}\right)$ and $\delta=a-\lambda b$. If $\lambda>1$ and $\delta \geq 0$, the distribution of men dominates that of women in the first order. Then, for $r \geq 1$, each married man is wealthier than his spouse. In the special case with $r=1$, the assignment function is linear, given by $\phi(z)=\lambda z+\delta$. We shall refer to this case as a linear shift or $L S$.

\subsubsection{Stability Conditions}

The allocations which support a stable assignment must be such that the implied expected lifetime utilities of the partners satisfy

$$
U_{h}(y)+U_{w}(z) \geq S(t) ; \quad \forall y, z,
$$

where $U_{h}(y)$ and $U_{w}(z)$ respectively represent the expected lifetime utilities of the husband and the wife over the two periods. For any stable marriage, equation (12) is satisfied as an equality, whereas for a pair that is not married, (12) would be satisfied as an inequality. In particular, we have

$$
\begin{aligned}
& U_{h}(y)=\max _{z}\left[S(t)-U_{w}(z)\right], \\
& U_{w}(z)=\max _{y}\left[S(t)-U_{h}(y)\right] .
\end{aligned}
$$

It is important to note that the stability conditions above constrain the total (twoperiod) expected utilities $U_{h}$ and $U_{w}$, but have no implication for the intertemporal distribution of utility over the two periods.

\footnotetext{
${ }^{9}$ Such a result is consistent with empirical findings on marriage and divorce patterns by schooling: individuals sort positively into marriage based on schooling and individuals with more schooling are less likely to divorce. See Browning, Chiappori, Weiss (in progress, ch. 1).
} 


\subsubsection{Determination of Expected Lifetime Utilities}

General Characterization Conditions in subsection (3.1.3) lead to an explicit characterization of the intra-household allocations. The envelope theorem applied to these conditions yields the differential equations :

$$
U_{h}^{\prime}(y)=S^{\prime}[y+\psi(y)]
$$

and

$$
U_{w}{ }^{\prime}(z)=S^{\prime}[\phi(z)+z] .
$$

To derive the expected spousal allocations over the two periods and along the assortative marital order, we integrate the expressions in (14) and (15). Hence, surplus share of a married man with income $y$ is

$$
U_{h}(y)=k^{h}+\int_{a}^{y} U_{h}^{\prime}(x) d x
$$

and the surplus share for a married woman with income $z$ is

$$
U_{w}(z)=k^{w}+\int_{b}^{z} U_{w}^{\prime}(x) d x,
$$

for some constants $k^{h}$ and $k^{w}$ which we determine below.

Pinning Down the Constants The constants $k^{h}$ and $k^{w}$ are pinned down by two conditions. First, for all married couples, the total output is known as expressed by equations (16) and (17). Hence,

$$
k^{h}+k^{w}=S[y+\psi(y)]-\int_{a}^{y} U_{h}^{\prime}(x) d x-\int_{b}^{\psi(y)} U_{w}^{\prime}(x) d x,
$$

where the left-hand side, by construction, does not depend on $y$. Secondly, it must be the case that 'the last married person is just indifferent between marriage and singlehood. In the case with more women than men, $r>1$, we have

$$
U_{w}\left(z_{0}\right)=2 z_{0} \quad \Leftrightarrow \quad k^{w}=2 z_{0}-\int_{b}^{z_{0}} U_{w}^{\prime}(x) d x,
$$

with $z_{0} \equiv \Phi(1-r)$. Hence, 


$$
\begin{gathered}
k^{h}=S\left[\phi\left(z_{0}\right)+z_{0}\right]-2 z_{0}, \\
U_{w}(z)=2 z_{0}+\int_{z_{0}}^{z} U_{w}^{\prime}(x) d x \\
U_{h}(y)=S[y+\psi(y)]-U_{w}[\psi(y)]=S[y+\psi(y)]-\left(2 z_{0}+\int_{z_{0}}^{\psi(y)} U_{w}^{\prime}(x) d x\right) .
\end{gathered}
$$

It is important to stress that the stability conditions apply without any assumption about the level of commitment attainable by the spouses or the option of remarriage. The insight is that the conditions on the first marriage market determine the allocation of lifetime utilities between spouses: because of competition, a wife would not agree to marry a husband who would provide less than the equilibrium utility (since many perfect substitutes exist), and neither would the husband.

\subsubsection{An example (A Linear Spousal-Income Shift with $r=1$ )}

The Framework In this special case, (11) becomes $\psi(y)=\frac{y-\delta}{\lambda}$ and equation (14) takes the form:

$$
U_{h}^{\prime}(y)=S^{\prime}\left(y+\frac{y-\delta}{\lambda}\right)=S^{\prime}(t),
$$

where $t=y+\frac{y-\delta}{\lambda}=\frac{\lambda+1}{\lambda} y-\frac{\delta}{\lambda}$ is the total household income. It follows that, using the change in variables $u=\frac{\lambda+1}{\lambda} x-\frac{\delta}{\lambda}$ :

$$
\begin{aligned}
U_{h}(y) & =k^{h}+\int_{a}^{y} S^{\prime}\left(x+\frac{x-\delta}{\lambda}\right) d x=k^{h}+\frac{\lambda}{\lambda+1} \int_{t_{m}}^{t} S^{\prime}(u) d u \\
& =k^{h}+\frac{\lambda}{\lambda+1}\left[S(t)-S\left(t_{m}\right)\right],
\end{aligned}
$$

where $t_{m}=a+b$ is the income of the poorest married couple. Similarly,

$$
U_{w}(z)=k^{w}+\frac{1}{\lambda+1}\left[S(t)-S\left(t_{m}\right)\right]
$$


And since utilities add up to $S(t)$, finally:

$$
\begin{aligned}
U_{h}(y) & =\frac{\lambda}{\lambda+1} S(t)+k, \\
U_{w}(z) & =\frac{1}{\lambda+1} S(t)-k .
\end{aligned}
$$

In words, each spouse's utility consists of a fixed share of the surplus plus or minus some constant. Note that the share reflects the local characteristics of the two distributions; specifically, it only depends on the linear shift parameter $\lambda$. The constant, on the other hand, is indeterminate since the numbers of males and females are exactly equal in this case. It is however bounded by the constraint that no married person would be better off as a single:

$$
\begin{aligned}
& U_{h}(y)=\frac{\lambda}{\lambda+1} S\left(\frac{\lambda+1}{\lambda} y-\frac{\delta}{\lambda}\right)+k \geq 2 y, \\
& U_{w}(z)=\frac{1}{\lambda+1} S((\lambda+1) z+\delta)-k \geq 2 z,
\end{aligned}
$$

for all $y, z$. Since $S^{\prime}(t) \geq 2$ for all $t$, it is sufficient to check these inequalities for $y=a$ and $z=b$. Therefore,

$$
\frac{\lambda}{\lambda+1} S\left(t_{m}\right)-2 a \leq k \leq \frac{1}{\lambda+1} S\left(t_{m}\right)-2 b
$$

where $t_{m}=a+b$ denotes the minimal household income in the population.

An Exogenous Increase in Female Income Using this form, we can describe the impact on intra-household allocations of an change in women's income. To keep things simple, we consider the linear spousal income shift framework $(L S)$, and we assume that all female incomes are multiplied by a given constant larger than one. In practice, this means that the coefficient $\lambda$ decreases (say by $-d \lambda$ ), while $\delta$ remains unchanged.

Since assortative matching is preserved, the identity of any individual's spouse is unaffected by this increase. However, while couples are unchanged, the intracouple allocation of resources may in principle respond to these changes in respective incomes. For small decreases in $\lambda$, one can actually directly compute the variation in intra-household allocation by differentiating equations (25) and (26) with respect to 
$\lambda$. Indeed, we have that:

$$
\begin{aligned}
d U_{h}(y) & =-\frac{\partial U_{h}(y)}{\partial \lambda} d \lambda \\
& =\frac{y-\delta}{\lambda(\lambda+1)} S^{\prime}\left(\frac{\lambda+1}{\lambda} y-\frac{\delta}{\lambda}\right) d \lambda-\frac{1}{(\lambda+1)^{2}} S\left(\frac{\lambda+1}{\lambda} y-\frac{\delta}{\lambda}\right) d \lambda .
\end{aligned}
$$

The variation in male utility is the sum of two terms. One reflects the increase in the couple's total income $t$; specifically, since Mr. $y$ now marries a wealthier wife, their total income $t=y+z=\frac{\lambda+1}{\lambda} y-\frac{\delta}{\lambda}$ grows by $d t=\frac{y-\delta}{\lambda^{2}} d \lambda$. The corresponding gain in surplus, equal to $S^{\prime}(t) d t$, is divided between the spouses according to the previous proportions; i.e., he gets $\frac{\lambda}{\lambda+1}$ and she gets $\frac{1}{\lambda+1}$ of the increase. However, the income shift also affects the sharing proportions themselves: since $\lambda$ shrinks, his share of the

total surplus is reduced by $\frac{1}{(\lambda+1)^{2}} d \lambda$, as reflected by the second term. Equivalently, one can write the change in female welfare as the sum of her share of the additional surplus and her gain from the shift in intra-household allocation:

$$
d U_{w}=\frac{y-\delta}{\lambda^{2}(\lambda+1)} S^{\prime}\left(\frac{\lambda+1}{\lambda} y-\frac{\delta}{\lambda}\right) d \lambda+\frac{1}{(\lambda+1)^{2}} S\left(\frac{\lambda+1}{\lambda} y-\frac{\delta}{\lambda}\right) d \lambda .
$$

In other words, besides the increase in household income, the shift results in a redistribution of the surplus in favor of the wife, the magnitude of which can readily be computed.

\subsection{The Intertemporal Allocation of Utility}

\subsubsection{The Commitment Issue}

We continue our analysis with the case in which remarriage is not an option and consider the allocation of lifetime utilities $U_{h}$ and $U_{w}$ between the two periods. At this point, commitment issues become crucial. While some degree of commitment is clearly achievable, there may be limits on the extent to which couples are able to commit - after all, couples could not and would not commit not to divorce. Two broad views emerge from the existing literature. Some contributors argue that only short-term commitment is attainable and that long-term decisions are generally open to renegotiation at a further stage. Others authors point out that a set of instruments, including prenuptial agreements, are available to sustain commitment. They, therefore, claim that divorce is the only limitation on commitment. Technically, marriage contracts should be seen as long-term efficient agreements under one constraint 
- namely that a person who wants to divorce can always choose to do so. ${ }^{10}$

In our framework, these two alternative views about commitment have a natural translation. Specifically, we can entertain two scenarios: In the first case ('commitment'), couples can commit to their spousal allocations in both periods conditional on the continuation of their marriage; the corresponding contingent allocations are ex-ante efficient under the sole constraint that divorce is unilateral. Therefore, the only constraint on intra-temporal allocation of resources is that second-period utility should exceed singles' utility, at least insofar as divorce is not an efficient outcome. Finally, should an unexpected event occur between the two periods, such as a reform of divorce laws (an example we consider below), this would not trigger a renegotiation of the initial agreement, unless the new individual rationality constraint is violated for one spouse. In the latter case, such a spouse would receive an additional share of household resources so that she becomes just indifferent between marriage and singlehood under the new law. ${ }^{11}$

In the alternative, polar case ('no commitment'), serious limits exist on the spouses' ability to commit. To capture this idea, we assume that couples can only commit to the immediate (i.e. first period) allocation of resources; future allocations cannot be contracted upon and will therefore be determined by a bargaining mechanism at the beginning of the second period. Of course, this feature is known ex ante by the agents and it influences the decisions regarding first-period allocations. Finally, if a reform occurs between the two periods, the new situation is taken into account during second-period bargaining; i.e., bargaining always take place 'in the shadow of the law'.

\subsubsection{Second-period Utilities}

The Commitment Case We first consider couples who can commit to their spousal allocations in marriage. No renegotiation can therefore take place unless divorce is credible. Moreover, if renegotiation does occur, it results in the minimal change needed for a marriage to continue, if that is indeed optimal.

Let $u_{h}^{2}(y)$ and $u_{w}^{2}(z)$ denote the monetary components of utility derived from the intra-marital allocations respectively of husband with endowment $y$ and wife with

\footnotetext{
${ }^{10} \mathrm{As}$ in standard contract theory, we do assume in all cases that a minimal level of commitment, whereby agents are able to at least commit to first-period allocations when they get married, is attainable. See Lundberg and Pollak (1993) for alternative assumptions. Also see Lundberg and Pollak (1993) and Mazzocco (2007) for further discussions of commitment issues within marriage.

${ }^{11}$ Similar ideas are used in different contexts, in particular risk sharing agreements under limited commitment. See Ligon et al. (2002) and Kocherlakota and Pistaferri (2008).
} 
endowment $z$ in the second period should they continue with their marriage. Hence, the husband's (wife's) total second-period utility is $u_{h}^{2}(y)+\theta$ (resp. $\left.u_{w}^{2}(z)+\theta\right)$ if the marriage continues. Feasibility constraints require that

$$
u_{h}^{2}(y)+u_{w}^{2}(z)=\eta(t) .
$$

Under unilateral divorce, each spouse can walk away with the share of family income determined by law, $\beta t$ for the wife and $(1-\beta) t$ for the husband, where $t=(y+z)$ is family income. Individual rationality implies that these outside options cannot exceed the utility payoffs if the marriage continues. Therefore, it must be the case that

$$
u_{h}^{2}(y)+\theta \geq(1-\beta) t \text { and } u_{w}^{2}(z)+\theta \geq \beta t,
$$

which we shall hereafter refer as the individual rationality constraints $(I R)$. Note that these conditions jointly imply that

$$
u_{h}^{2}(y)+u_{w}^{2}(z)+2 \theta=\eta(t)+2 \theta \geq t,
$$

or equivalently that $\theta \geq \hat{\theta}(t)$, so that divorce is not the efficient outcome.

Any allocation such that (29) is satisfied can be implemented as part of a feasible marital contract. A natural question, however, is whether the material allocation $\left(u_{h}^{2}, u_{w}^{2}\right)$ can be contingent upon the realization of $\theta$. Contingent allocations raise specific problems. For instance, depending on the enforcement mechanism, they may require that the quality of the match be verifiable by a third party. Whether such verifiability is an acceptable assumption is not clear. It turns out, however, that under our assumption of common $\theta$, verifiability is not an issue because there exists (exactly) one allocation allocation that satisfies the incentive compatibility constraints for all $\theta$. That is,

Proposition 1 With commitment and unilateral divorce, there exists exactly one allocation that is not $\theta$-contingent and guarantees that all the constraints are satisfied for any realization of $\theta$.

Proof. The key remark is that the time consistency constraints (29) must be binding when $\theta=\hat{\theta}(t)$ since, for that value, the couple is indifferent between marriage and divorce. Hence,

$$
\begin{gathered}
u_{h}^{2}(y)=(1-\beta) t-\hat{\theta}(t)=\frac{1}{2}(\eta(t)+(1-2 \beta) t), \\
u_{w}^{2}(z)=\beta t-\hat{\theta}(t)=\frac{1}{2}(\eta(t)-(1-2 \beta) t) .
\end{gathered}
$$


Note that, for any realization of $\theta$, either $\theta<\hat{\theta}(t)$ and divorce takes place or $\theta \geq \hat{\theta}(t)$ and utilities are equal to $(1-\beta) t+\theta-\hat{\theta}(t)$ and $\beta t+\theta-\hat{\theta}(t)$ for the husband and the wife respectively, so that the time consistency constraints are fulfilled for both spouses.

Interestingly, the second-period utilities in marriage exactly reflect the utilities if divorced, with the addition of the difference between the actual match quality $\theta$ and the threshold $\hat{\theta}$. In particular, any increase of, say, the wife's utility in divorce is exactly reflected in her second-period utility even if divorce does not take place.

No Commitment For couples who won't divorce but also cannot make pre-marital allocative commitments, renegotiation systematically takes place at the beginning of the second period. We assume that such couples reach a Nash-bargaining solution with the utility of the husband and the wife in case of divorce as the relevant threat points. Hence, the allocations which we denote $\left(v_{h}^{2}(y), v_{w}^{2}(z)\right)$, satisfy

$$
v_{h}^{2}(y)+v_{w}^{2}(z)=\eta(t)
$$

and solve

$$
\max _{v_{h}^{2}(y), v_{w}^{2}(z)}\left[v_{h}^{2}(y)+\theta-(1-\beta) t\right]\left[v_{w}^{2}(z)+\theta-\beta t\right] .
$$

The solution is given by the following statement:

Proposition 2 In the no-commitment case, the Nash-bargained, second-period utilities are:

$$
\begin{aligned}
& v_{h}^{2}(y)=\frac{1}{2}[\eta(t)+(1-2 \beta) t], \\
& v_{w}^{2}(z)=\frac{1}{2}[\eta(t)+(2 \beta-1) t] .
\end{aligned}
$$

Proof. The program maximizes the product of two terms, the sum of which is constant and equal to $\eta(t)+2 \theta-t$. Therefore

$$
v_{h}^{2}(y)+\theta-(1-\beta) t=\frac{\eta(t)+2 \theta-t}{2}=v_{w}^{2}(z)+\theta-\beta t,
$$

hence, the conclusion. 
These values are exactly the same as in the non $\theta$-contingent allocation under commitment. In other words, the unique second-period allocation that is not $\theta$ contingent and guarantees that the individual rationality constraints are satisfied for any realization of $\theta$ is also the Nash solution to a second-period bargaining. ${ }^{12}$

For completeness, let us briefly discuss the case of different valuations of the match quality by the husband and wife. In this case, individual utilities take the form

$$
U_{i}=u_{i}\left(q_{i}, Q\right)+\theta_{i}, \quad i=h, w,
$$

where the pair $\left(\theta_{h}, \theta_{w}\right)$ is jointly distributed over some support in $\mathbb{R}^{2}$ which need not be the diagonal. If we denote $\theta=\left(\theta_{h}+\theta_{w}\right) / 2$ the average valuation, the total surplus generated by marriage is $\eta(t)+\theta_{h}+\theta_{w}=\eta(t)+2 \theta$. In particular, the analysis of divorce probabilities and lifetime utilities remains unchanged, since in our Becker-Coase framework they are driven by the total marital surplus only. The main difference relates to the inter-temporal distribution of welfare. Specifically, secondperiod utilities in the no commitment case are given by:

$$
\begin{aligned}
& v_{h}^{2}(y)=\frac{1}{2}\left[\eta(t)+(1-2 \beta) t+\left(\theta_{w}-\theta_{h}\right)\right], \\
& v_{w}^{2}(z)=\frac{1}{2}\left[\eta(t)+(2 \beta-1) t+\left(\theta_{h}-\theta_{w}\right)\right] .
\end{aligned}
$$

These allocations are contingent on the realization of $\left(\theta_{h}, \theta_{w}\right)$ reflecting the fact that, should the marriage continue, a spouse whose evaluation is poor must be compensated by an adequate monetary transfer. Again, this allocation can be implemented in the commitment case as well, although it is now $\theta$-contingent (it requires transfers that depend on the difference in the valuations of the husband and wife).

\subsubsection{First-period Utilities}

For each choice of $k$, we can now recover the first-period allocations. The expected two-period utilities equal

$$
\begin{gathered}
U_{h}(y)=u_{h}^{1}(y)+\bar{\theta}+(1-\alpha(t))\left\{u_{h}^{2}(y)+E[\theta \mid \theta \geq \hat{\theta}(t)]\right\}+\alpha(t)(1-\beta) t \\
U_{w}(z)=u_{w}^{1}(z)+\bar{\theta}+(1-\alpha(t))\left\{u_{w}^{2}(z)+E[\theta \mid \theta \geq \hat{\theta}(t)]\right\}+\alpha(t) \beta t
\end{gathered}
$$

\footnotetext{
${ }^{12}$ The Nash Bargaining outcome is independent of common changes in $\theta$ because of Nash's symmetry requirement.
} 
where $\alpha(t)=\operatorname{Pr}(\theta<\hat{\theta})$ is the divorce probability. These utilities must coincide with the equilibrium values derived above. Therefore, for $r>1$,

$$
\begin{gathered}
u_{w}^{1}(z)=z_{0}+\int_{z_{0}}^{z} S^{\prime}[\phi(x)+x] d x \\
-(1-\alpha(t))\left\{u_{w}^{2}(z)+E[\theta \mid \theta \geq \hat{\theta}(t)]\right\}-\alpha(t) \beta t \\
u_{h}^{1}(y)=S[y+\psi(y)]-z_{0}-\int_{z_{0}}^{\psi(y)} S^{\prime}[\phi(x)+x] d x \\
+(1-\alpha(t))\left\{u_{h}^{2}(y)+E[\theta \mid \theta \geq \hat{\theta}(t)]\right\}-\alpha(t)(1-\beta) t .
\end{gathered}
$$

\subsection{An Application: Reforming Divorce Laws}

Various reforms of divorce laws have been discussed and implemented in the past. Much of the analysis of these focused on the impact of the switch from mutual consent to unilateral divorce. ${ }^{13}$ Here, though, we focus on the impact of the changes in the division of the property rights over family assets, including human capital. In several countries, the law has shifted towards viewing all family assets as common to some extent, implying that each partner has some property rights over the income of his or her spouse if the marriage dissolves. ${ }^{14}$ We consider a change in divorce laws such that the share of aggregate household resources rewarded to the wives is increased

\footnotetext{
${ }^{13}$ Peters (1986), Friedberg (1998) and Wolfers (2006) represent some of the key contributions in this strand.

${ }^{14}$ Among the United States, nine states including Arizona, California, Idaho, Louisiana, Nevada, New Mexico, Texas, Washington and Wisconsin are "community property" states where assets and wealth accumulated during marriage are split equally. All other states, except Mississippi are "equitable distribution" states where property division "ought to be fair and equitable but not necessarily equal." In Mississippi, property division is based on the ownership of legal title, but if title is jointly held, division upon divorce is equal.

Many other countries, such as the Netherlands, the United Kingdom, Sweden and Turkey, have adopted some variant of the "community property" rule according to which marital assets and wealth are split 50-50 between the spouses. Moreover, the legal requirements for divorce have been relaxed in many countries. For example, the adoption of the no-fault unilateral divorce laws in the United States in the 1970s granted individuals the right to seek a divorce without the consent of their spouses. This marked a dramatic departure from earlier divorce laws which required the consent of both parties to a divorce. In the United Kingdom the Divorce Reform Act, which made divorce possible after two years of separation in the case of dual consent and after five years in the case of no consent, was passed in 1969. The Matrimonial and Family Proceedings Act, which reduced the required wait in either case to twelve months, was enacted in 1984.
} 
from $\beta$ to $\hat{\beta}$. Note, however, that $\beta$ may be couple-specific (as it would be in a private-property regime). If remarriage is not an option, the Becker-Coase theorem applies and such a change does not affect divorce probabilities. In particular, the threshold $\hat{\theta}(t)$ only depends on the surplus generated by marriage, not on its postdivorce division between (ex-)spouses; a couple splits if and only if its realized $\theta$ lies below the threshold, irrespective of the $\beta$ in place. But, under unilateral divorce laws, changes in $\beta$ typically result in a redistribution of the surplus between spouses during marriage. Whether a wife would benefit from the new property division rules would depend on her income, her marriage match quality, and the level of commitment achieved between the spouses.

Concerning the impact on the division of marital gains, it is crucial to distinguish between existing couples, who are already married when the change becomes effective and those who are not yet married. For the former, unexpected legislative changes may trigger a renegotiation within the household and alter the original contract implemented. For the latter, the new legislation would be taken into account at the matching stage and reflected in the expected allocations entering marriage. We now consider these two cases successively.

\subsubsection{Existing Marriages}

Consider a married couple with endowments $y$ and $z$ for the husband and wife, respectively, whose match quality $\theta$ strictly exceeds the threshold $\hat{\theta}(t)$. Since the intra-household spousal allocations, as determined in the marriage market, were individually rational, it must have been the case that neither spouse had an incentive to get divorced with the original $\beta$ in place.

Commitment Assume, first, that the spouses feel committed by the contract they initially chose, although they do not feel obligated to remain married. If $\theta$ is large enough, the wife's individual rationality requirements given by (29) are satisfied for both $\beta$ and $\hat{\beta}$. This occurs if

$$
\theta \geq \hat{\beta} t-u_{w}^{2}(z)
$$

where $u_{w}^{2}(z)$ denotes the continuation utility of the wife under the current agreement. Then, due to the commitment assumption, the change in divorce laws has no impact on intra-household allocations. If, on the contrary, $\theta$ is such that

$$
\hat{\beta} t-u_{w}^{2}(z)>\theta \geq \beta t-u_{w}^{2}(z)
$$


then the initial agreement is no longer enforceable, since it would violate the wife's individual rationality. Hence, her second-period allocation must be adjusted upward to $\hat{u}_{w}^{2}(z)=\hat{\beta} t-\theta$, which requires an additional transfer equal to

$$
T=(\hat{\beta}-\beta) t-\theta-\frac{\eta(t)-t}{2} \geq 0
$$

From a comparative perspective, the probability of a renegotiation taking place depends on the distribution of $\theta$. In the benchmark case where $\theta$ is more or less uniform over a 'large enough' support, the probability is proportional to $(\hat{\beta}-\beta) t$. When both $\beta$ and $\hat{\beta}$ are identical across couples, the reform affects a larger proportion of higher-income couples. Regarding the size of the transfer, one can readily check that if $\beta$ and $\hat{\beta}$ are identical across couples, the transfer $T$ given by (43) is concave in total wealth $t$. It increases in $t$ for small $t$ but if the surplus function $\eta(t)$ is convex enough, it decreases in $t$ when $t$ is large enough. Then, the magnitude of the transfer is non-monotonic in income; it is smaller for the poorest and the highest-income couples and maximal for intermediate income levels. In the special case of a move from private to common property, then $\beta=z /(y+z)$, the reform, not surprisingly, is more likely to affect those couples for whom the initial distribution of incomes was biased in favor of the husband. The transfer can be written as

$$
T=\hat{\beta} t-z-\theta-\frac{\eta(t)-t}{2} .
$$

It is still concave in $t$. Moreover, for any given $t$, it decreases in $z$, implying that it is larger for initially unequal couples.

We conclude that the reform will affect intra-household allocations of some - but not all - couples. For couples with a low realized match quality, the second-period marital allocation of the wife may no longer be sustainable in marriage. As a result, there will be more recontracting in favor of women among such couples. And since first-period spousal allocations would have already been sunk for all of the existing marriages at the time of the legislative change, a more generous settlement rule for the wives would imply higher allocations for them in the second period and over their lifetimes.

No Commitment In the absence of commitment, renegotiation takes place between all spouses. The reform directly impacts the respective threat points. Therefore, it affects all couples. Assuming, as above, a Nash bargaining solution with 
utilities in case of divorce as threat points, we see that the wife's gain from the reform is

$$
\hat{v}_{w}^{2}(z)-v_{w}^{2}(z)=(\hat{\beta}-\beta) t,
$$

while the husband loses the same amount.

We conclude that when a reform of divorce laws is favorable to women and there is no commitment to ex-ante spousal allocations between spouses, all wives will benefit and all husbands will lose. This exemplifies the case of 'bargaining in the shadow of the law'.

\subsubsection{Future Marriages}

Now consider a couple who is not yet married at the time of the legislative change. The expected lifetime allocations of such a couple, as given by equations (38) and (39), can be decomposed into three parts: the first-period utility, the second-period utility if marriage is continued, and the second-period utility in case of divorce. Unlike existing marriages, however, this effect is fully anticipated by the agents in the matching phase and reflected in the equilibrium allocations. This has two consequences. First, the reform influences intra-household allocation in both periods. This is because the allocation of lifetime utility, which involves first- and second-period welfare, is decided during the matching process, taking into account the new law. A second and more subtle implication is that the impact of the reform on a future marriage is the same whether or not agents are able to commit to specific intra-household allocations ex ante. Indeed, we have seen in subsection 3.2.2 that the (non- $\theta$-contingent) allocation decided ex ante is the same in both contexts.

Using (31) and (32), we can compute the impact of a change in post-divorce allocations on individual utilities. If $\beta$ is identical across couples before and after the reform - one may think of a redefinition of 'equitable distribution' in a sense more favorable to women - the variations in individual utilities are given by:

$$
\Delta u_{h}^{1}=\Delta u_{w}^{2}=(\hat{\beta}-\beta) t, \quad \Delta u_{h}^{2}=\Delta u_{w}^{1}=-(\hat{\beta}-\beta) t,
$$

while if the switch is from private to common property, then,

$$
\Delta u_{h}^{1}=\Delta u_{w}^{2}=\hat{\beta} t-z, \quad \Delta u_{h}^{2}=\Delta u_{w}^{1}=-(\hat{\beta} t-z),
$$

In both cases, a divorce law that mandates more generous divorce settlements for women increases their utility in the second period whether or not the couple divorces. However, the reform also lowers their first-period allocations by the same 
amount. Implicit in the above argument is what we have already established in (20): in marriages not yet formed, a legislative change has no effect on the expected lifetime allocations of each spouse, $U_{h}(y)$ and $U_{w}(z)$. But given that equilibrium spousal allocations need to be individually rational, more favorable divorce rules may lead to a more rapidly rising allocation path for the wives-to-be in order to ensure that their marital commitments are time consistent; in practice, they get more at the end but less at the beginning of the union. In particular, all wives' expected intra-marital allocations conditional on remaining married are reduced and the reduction exactly offsets their gain in case of divorce.

We conclude with the following general proposition:

Proposition 3 A change in the rules governing property rights over the distribution of family assets has no impact on welfare as measured by expected lifetime utilities at the time of marriage. To the extent that the policy raises the utility of women following divorce, it must reduce their total utility while married.

The neutrality of mandated divorce settlements is similar to Lazear's (1990) result on the neutrality of mandated severance payments in the context of worker-firm relationships. In both cases, an attempt by the government to redistribute income among agents is completely undone by a redistribution over time within families or firms and does not affect the competitive outcome. ${ }^{15}$

\section{Divorce with Potential Remarriage}

We now relax the assumption that divorcees must remain single during the second period. Instead, we introduce a remarriage market at the beginning of the second period, when all singles - never married individuals and recent divorcees - can find a new spouse.

The analysis of a matching model with remarriage is difficult in general, because the possibility of remarriage has a complex impact on the initial marital choice in particular. To deal with this issue, we first consider a particular case characterized by two additional assumptions under which the model can be completely solved. Then,

\footnotetext{
${ }^{15}$ The same point is made by Lundberg and Pollak (1993) regarding child allowances. These neutrality results are also related to the literature on Ricardian equivalence (see Barro, 1974) in that an attempt by the government to redistribute income among agents is completely undone by a redistribution over time within family units. Note, however, that our result relies on market forces rather than altruism to endogenize redistribution between spouses.
} 
we briefly discuss the general framework and present some numerical examples which elaborate on the generalized results.

\subsection{A Special Case}

In this subsection, we maintain the following two assumptions:

A1 The average match quality $\bar{\theta}$ is 'large' so that all agents are willing to marry in the first period.

A2 Define, as above, $z_{0}=G^{-1}(1-1 / r)$. Then $\beta\left(z_{0}+a\right)>z_{0}$.

A characteristic feature of remarriage markets is that they may generate 'strategic postponement' whereby some agents decide not to marry during the first period in order to improve their marital prospects in the second. A large enough expected first-period surplus eliminates such strategies, which is the motivation of Assumption A1. Regarding A2, note that if matching is assortative, the last married woman has income $z_{0}$ and she marries a man with the lowest income $a$. Thus, A2 stipulates that she is wealthier after divorce than before. A consequence is that in the remarriage market, she will be in a better position than any never married woman, which helps to pin down the pattern of remarriage matching.

Indeed, we shall see that under Assumptions A1 and A2, one can fully characterize the stable matches. A technical difficulty is that, while the game must be solved by backward induction starting with the remarriage matching game, the analysis of remarriage depends on post-divorce income distributions which themselves reflect the characteristics of the initial match (especially, whether or not it was assortative). It is important to note, however, that since utility remains transferable, the stable matching profile maximizes total surplus; therefore it is generically unique. Our strategy is, thus, to (i) assume that lifetime surplus is increasing and supermodular so that initial matching is positively assortative; (ii) solve the game backward under this assumption; and (iii) show that the resulting total surplus is indeed supermodular; if a candidate equilibrium satisfies all the stability conditions, it must be the unique equilibrium.

For expositional simplicity, we start with the case $r=1$ - i.e., there are equal measures of men and women so that all agents marry initially. Couples who draw a poor match quality may divorce. In that case, they enter the remarriage market with their post-divorce allocations, respectively equal to $y^{D}=(1-\beta)(y+z)$ for men and 
$z^{D}=\beta(y+z)$ for women. Then, the static matching game is played once. Note, however, that the income distributions are not the same as the initial one because of the transfers between spouses induced by divorce settlements.

\subsubsection{Equal Numbers of Men and Women $(r=1)$}

Remarriage We start with the remarriage game. In the remarriage market, there are equal numbers of men and women, because each divorce increases the male and female supplies by one unit each. Moreover, for each gender, individual income rankings are not modified. Indeed, if a couple $(y, z)$ was initially wealthier than $(\bar{y}, \bar{z})$, it must be the case that $y \geq \bar{y}$ and $z \geq \bar{z}$ due to assortative matching. If both couples divorce, the first husband, with an income $y^{D}=(1-\beta)(y+z)$, remains wealthier than the second, whose income is only $\bar{y}^{D}=(1-\beta)(\bar{y}+\bar{z})$ and similarly for the wives. It follows that the number of men wealthier than $y^{D}$ equals the number of women wealthier than $z^{D}$. Since matching is assortative in the remarriage market due to the supermodularity of the one-period surplus $\eta$, we conclude that each divorced man marries a 'clone' of his former wife - i.e., a woman who just divorced a husband with the same initial income as his own.

In terms of income, if his initial income was $y$ and hers was $z$, now his income is $(1-\beta)(y+z)$. Moreover, the current incomes of his new and of his ex wife are both equal to $\beta(y+z)$ (and analogous comparisons apply to women). If $y^{D}=\phi^{R}\left(z^{D}\right)$ (or equivalently $\left.z^{D}=\psi^{R}\left(y^{D}\right)\right)$ denotes the new assignment, we simply have

$$
y^{D}=\phi^{R}\left(z^{D}\right)=\frac{1-\beta}{\beta} z^{D} \quad \text { or equivalently } \quad z^{D}=\psi^{R}\left(y^{D}\right)=\frac{\beta}{1-\beta} y^{D} .
$$

Note that, in general, $\beta$ may vary across couples. In the particular case where $\beta$ is identical across couples, we see that irrespective of the initial income distributions and the corresponding assignment profile, the male and female distributions of income in the remarriage market are deduced from each other by a linear transform, and we are therefore in the linear shift $(L S)$ case studied above.

The new intra-household allocation of resources is again driven by the stability conditions in the remarriage market. Specifically, let $u_{h}^{R}\left(y^{D}\right)$ and $u_{w}^{R}\left(z^{D}\right)$ respectively denote the monetary components of the husbands' and wives' equilibrium utilities after remarriage, so that the true utilities are $u_{h}^{R}\left(y^{D}\right)+\theta^{R}$ and $u_{w}^{R}\left(z^{D}\right)+\theta^{R}$, where $\theta^{R}$ is the match quality of the new marriage. Stability requires that

$$
u_{h}^{R}\left(y^{D}\right)=\max _{z^{D}}\left[\eta\left(y^{D}+z^{D}\right)-u_{w}^{R}\left(z^{D}\right)\right]
$$


and

$$
u_{w}^{R}\left(z^{D}\right)=\max _{y^{D}}\left[\eta\left(y^{D}+z^{D}\right)-u_{h}^{R}\left(y^{D}\right)\right] .
$$

Again, the envelope theorem gives

$$
\frac{d u_{h}^{R}\left(y^{D}\right)}{d y^{D}}=\eta^{\prime}\left(y^{D}+z^{D}\right)=\frac{d u_{w}^{R}\left(z^{D}\right)}{d z^{D}} .
$$

Therefore,

$$
\begin{aligned}
& u_{h}^{R}\left(y^{D}\right)=\int_{(1-\beta)(a+b)}^{y^{D}} \eta^{\prime}\left[u+\psi^{R}(u)\right] d u+K^{h}, \\
& u_{w}^{R}\left(z^{D}\right)=\int_{(1-\beta)(a+b)}^{z^{D}} \eta^{\prime}\left[\phi^{R}(u)+u\right] d u+K^{w} .
\end{aligned}
$$

If $\beta$ is identical across couples, we can use the linear transform property, and we finally get that

$$
\begin{aligned}
& u_{h}^{R}\left(y^{D}\right)=(1-\beta) \int_{a+b}^{t} \eta^{\prime}(u) d u+K=(1-\beta) \eta(t)+K, \\
& u_{w}^{R}\left(z^{D}\right)=\beta \int_{a+b}^{t} \eta^{\prime}(u) d u-K=\beta \eta(t)-K,
\end{aligned}
$$

for some constant $K$. Here $t=y^{D} /(1-\beta)=z^{D} / \beta=y^{D}+z^{D}$ is the total income of the new couple $\left(y^{D}, z^{D}\right)$. In words, she gets a fraction $\beta$ and he gets a fraction $1-\beta$ of the surplus plus some positive or negative constant $K$. Since men and women are in equal number, the exact value of the constant $K$ is indeterminate, but it must be such that no remarried man or woman are better off as single, which implies that

$$
\beta[\eta(A+B)-(A+B)] \geq K \geq(1-\beta)[(a+b)-\eta(a+b)],
$$

where $(A, a)$ and $(B, b)$ are the lower and upper bounds of the male and female incomes, respectively.

Divorce We now consider the divorce decision. Let $u_{h}^{2}(y)$ and $u_{w}^{2}(z)$ denote, as before, the monetary components of utility derived from the intra-marital allocations respectively of the husband with endowment $y$ and the wife with endowment $z$ in the second period should they continue with their marriage. Under unilateral divorce, individual rationality requires that spouses cannot remain married unless

$$
u_{h}^{2}(y)+\theta \geq u_{h}^{R}\left(y^{D}\right)+\bar{\theta} \quad \text { and } \quad u_{w}^{2}(z)+\theta \geq u_{w}^{R}\left(z^{D}\right)+\bar{\theta} .
$$


This can be satisfied only if

$$
\begin{aligned}
u_{h}^{2}(y)+u_{w}^{2}(z)+2 \theta & =\eta(y+z)+2 \theta \\
& \geq \\
u_{h}^{R}\left(y^{D}\right)+u_{w}^{R}\left(z^{D}\right)+2 \bar{\theta} & =\eta(y+z)+2 \bar{\theta}
\end{aligned}
$$

which boils down to $\theta \geq \bar{\theta}$ : couples divorce if and only if the quality of their current match is below the mean, thus exploiting the option to redraw provided by divorce. The divorce probability is therefore identical for all couples; if the distribution of $\theta$ is symmetric around its mean, the probability is now .5 for all couples. Note that, although the second-period utilities are no longer transferable between former spouses - neither $u_{h}^{2}(y)$ nor $u_{w}^{2}(z)$ are linear in general - the framework still satisfies the Becker-Coase property that divorce is independent of the laws governing settlements. This property, however, is due to the fact that each person remarries a clone of their former spouse; it would not hold in more general settings.

First-period Marriage We can now analyze the first-period matching game. Several remarks can be made:

- Despite the possibilities opened by the existence of a remarriage market, utility is still transferable in this game because of the transferable structure of firstperiod utilities.

- Moreover, the lifetime surplus generated by a first-period marriage still depends only on total income $t=y+z$. It is actually given by

$$
\begin{aligned}
S^{R}(t) & =\eta(t)+2 \bar{\theta}+\frac{1}{2}[\eta(t)+2 E[\theta \mid \theta \geq \bar{\theta}]]+\frac{1}{2}(\eta(t)+2 \bar{\theta}) \\
& =2 \eta(t)+3 \bar{\theta}+E[\theta \mid \theta \geq \bar{\theta}]
\end{aligned}
$$

In particular, the surplus is supermodular since $\eta$ is convex, and the assortative matching conclusion is verified.

- The allocation of the lifetime surplus between spouses is now

$$
U_{h}^{R}(y)=k^{h}+2 \int_{a}^{y} \eta^{\prime}[x+\psi(x)] d x \quad \text { and } \quad U_{w}^{R}(z)=k^{w}+2 \int_{b}^{z} \eta^{\prime}[\phi(x)+x] d x,
$$


where the constants $k^{h}$ and $k^{w}$ satisfy:

$$
k^{h}+k^{w}=2 \eta(t)+3 \bar{\theta}+E[\theta \mid \theta \geq \bar{\theta}]-\int_{a}^{y} \eta^{\prime}[x+\psi(x)] d x-\int_{b}^{z} \eta^{\prime}[\phi(x)+x] d x
$$

- Finally, the analysis of the inter-temporal allocation goes through as before. Taking, for instance, the non-commitment, Nash bargained solution, we find that the second-period allocation, which we denote $\left(v_{h}^{2 R}(y), v_{w}^{2 R}(z)\right)$, solves

$$
\max _{v_{h}^{2}(y), v_{w}^{2}(z)}\left[v_{h}^{2}(y)+\theta-(\beta \eta(t)+K+\bar{\theta})\right]\left[v_{w}^{2}(z)+\theta-((1-\beta) \eta(t)-K+\bar{\theta})\right],
$$

which gives

$$
v_{h}^{2}(y)=\beta \eta(t)+K \quad \text { and } \quad v_{w}^{2}(z)=(1-\beta) \eta(t)-K
$$

for some constant $K$. Again, this allocation satisfies the equilibrium conditions of the commitment case and it is not contingent on $\theta$.

\subsubsection{More Women than Men $(r>1)$}

Now consider $r>1$. Some women will remain single at the end of the first period and may enter the remarriage market during the second period. In this context, we show that the stable matching profile entails assortative matching and that its main characteristics are actually the same as when $r=1$. Indeed, if the first-period surplus is increasing and supermodular, single women are all at the bottom of the female income distribution. That is, there exists a threshold $z_{0}$ such that a woman is married if and only if her income is above $z_{0}$. At the beginning of the second period, all never married women have an income below $z_{0}$, whereas all divorcees have an income equal to $\beta\left(z_{0}+a\right)$, which is larger than $z_{0}$ due to assumption $A 2$. Therefore, the support of the second-period female income distribution consists of two disjoint intervals, $\left[b, z_{0}\right]$ and $\left[\beta\left(z_{0}+a\right), \beta(A+B)\right]$. Since the second-period surplus $\eta$ is supermodular and increasing, the second-period matching is positively assortative and only women in the $\left[\beta\left(z_{0}+a\right), \beta(A+B)\right]$ interval — all recent divorcees - remarry. In particular, the shares on the remarriage market are still indeterminate within some bounds, because the poorest 'marriageable' women with income $\beta\left(z_{0}+a\right)$ do not have close substitutes. However, in the initial marriage market, the shares are exactly determined by the standard argument that the 'last married' woman does not gain from marriage. 
In other words, the first-period marriage market splits the female population into two disjoint subsamples. Women who do not marry in the first period will remain single forever; the marriage market and the remarriage markets are de facto limited to women whose initial incomes are above $z_{0}$. By definition, such women are exactly as numerous as men. We conclude that the previous analysis, in which $r$ was equal to 1, exactly applies in this case too. And, as seen before, the first-period surplus is indeed supermodular and increasing.

\subsection{The General Case}

If assumptions A1 or A2 fail to hold, the model becomes more complex. Indeed, divorce may now change the relative rankings by income both for men and for women. As a result, it is no longer the case that divorced men remarry a 'clone' of their exwives. A first consequence is that the Becker-Coase property (that divorce probability is independent of the legal system) does not hold. Changes in divorce settlements (our $\beta$ ) modify individual utilities in the remarriage market in a non-transferable way. Actually, the lifetime surplus generated by the initial marriage, while still transferable, also depends on $\beta$. Secondly, assortative matching is not guaranteed to hold; indeed, when the impact of the couple-specific divorce probability is taken into account, the lifetime surplus may fail to remain supermodular. Thirdly, agent's first-period marital strategy becomes more complex because some agents may choose to strategically postpone marriage. For instance, a never married man may have a much better ranking in the remarriage market than in the initial marriage market, especially if, in the latter market, most of his competitors are recent divorcees whose incomes are fairly depleted by divorce settlements. ${ }^{16}$ While the stable matching profile is still generically unique (because of transferability), its determination must therefore rely on a fixed-point argument, whereby the agents' initial anticipations regarding the remarriage market turn out to be self-fulfilling. To highlight some of these results, we shall next discuss a numerical example (see Kapan, 2008, for further investigations).

\footnotetext{
${ }^{16}$ Rasul (2006) and Matouschek and Rasul (2008) identify a similar finding whereby changes in the cost of divorce affect not only the incentive of those existing couples to stay married, but also the flow of those individuals that are selected into the marriage market.
} 


\subsubsection{A Numerical Example}

We use a rudimentary structural model to trace the equilibria in an assignment model with divorce and remarriage and apply it to illustrate the role of changes in divorce laws on outcomes. To proceed, we assume that the husbands' and wives' individual utilities take the following specific form:

$$
U_{i}=q_{i} Q+\theta, \quad i=h, w,
$$

where $q_{i}$ represents member $i$ 's private consumption, $Q$ is the public good consumed jointly (shared) by the couple, and $\theta$ is the quality of the couple-specific match.

For any single individual, $s$, preferences take the strictly quasi-linear form:

$$
u_{s}=q_{s}+Q_{s} .
$$

Upon marriage, the marginal utility from the private good consumed by each spouse, $q_{i}$, equals the joint consumption of the public good, $Q$, which is the same for both partners. Hence, together with the specification of singles' utility in (52), utility is transferable within and without marriage. ${ }^{17}$

If man $i$ marries woman $j$, their joint income is $w_{i}+w_{j}$. With transferable utility, any efficient allocation of the family resources maximizes the partners' sum of utilities given by $\left(w_{i}+w_{j}-Q\right) Q+2 \theta$. In an interior solution with positive expenditure on the public good, the maximized material output is

$$
\zeta_{i j}=\frac{\left(w_{i}+w_{j}\right)^{2}}{4} .
$$

Note that the wages of the husband and wife complement each other in generating marital output, which is a consequence of sharing the public good.

For simplicity, we assume that $\theta$ is uniformly and independently distributed over the interval $[-5,5]$. All women are identical and have a wage rate of $w=3$. Half of the men are high-wage earners, $w_{h}=5$, and the other half are low types, $w_{l}=3$. The measure of women exceeds that of men so that the sex ratio exceeds unity, with $r=1.3>1$. These parameter values are displayed in Table 1 .

\footnotetext{
${ }^{17}$ If singles' utility was given by $u_{i}^{s}=q_{i} Q_{i}$, then as shown in Chiappori et al. (2007), utility is not transferable upon divorce, which would move us a way from the Becker-Coase environment that we wish to investigate.
} 
Table 1: Fixed Parameters

\begin{tabular}{|l|c|}
\hline Parameter & \\
\hline Wage of women & $w=3$ \\
\hline Wage of low-wage men & $w_{l}=3$ \\
\hline Wage of high-wage men & $w_{h}=5$ \\
\hline Fraction of high-wage men & .5 \\
\hline Sex ratio & $r=1.3$ \\
\hline Distribution of match quality & {$[-5,5]$} \\
\hline
\end{tabular}

Suppose that, initially, the divorce laws are such that they entitle women to $\beta=.4$ fraction of total income in case of divorce and the rest, $1-\beta=.6$, to men. We compare that regime with two others in which $\beta$ varies from .5 to .55 , alternatively. Although women are assumed to be ex-ante identical, following divorce and redistribution, their second period income can rise or fall so that heterogeneity is created ex-post. Similarly, the income of men can fall or rise following divorce and redistribution. Given our chosen parameters, the income of high-wage men always declines following divorce. However, the income of the low-wage men can rise following divorce if he can appropriate more than half of the family assets. e.g., $\beta=.4$ (See Table 2).

Changes in the income redistribution influence the joint material output that partners can obtain in their first and second marriages. As we argued earlier, the marital output and surplus in each period is an increasing convex function of the sum of the incomes of the partners. Hence, it is sufficient to record what happens to the total family income of married partners. Note, first, that in the first period of marriage, a match between a high-wage man and any woman yields a family income of 8 , while a match between a low-wage man and any woman yields a family income of 6 . As seen in Table 2, matches in the second period yield family incomes that fall in between these two bounds. We see that the output of matches involving a high-wage man and an ex-wife of a low-wage man declines as the share of the wife rises, because the gain of the wife for such couples falls short of the losses of the husband. The opposite pattern is observed for couples consisting of a low-wage man and an ex- wife of a high-wage man. 
Table 2: Impact of Redistribution on Post-Divorce Incomes

\begin{tabular}{|l|c|c|c|}
\hline & $\beta=.4$ & $\beta=.5$ & $\beta=.55$ \\
\hline Ex-wife of a $w_{h}$ man & 3.2 & 4 & 4.4 \\
\hline Ex-wife of a $w_{l}$ man & 2.4 & 3 & 3.3 \\
\hline$w_{h}$ man & 4.8 & 4 & 3.6 \\
\hline$w_{l}$ man & 3.6 & 3 & 2.7 \\
\hline$w_{h}$ man and ex-wife of a $w_{h}$ man & 8 & 8 & 8 \\
\hline$w_{h}$ man and ex-wife of a $w_{l}$ man & 7.2 & 7 & 6.9 \\
\hline$w_{l}$ man and ex-wife of a $w_{h}$ man & 6.8 & 7 & 7.1 \\
\hline$w_{l}$ man and ex-wife of a $w_{l}$ man & 6 & 6 & 6 \\
\hline divorced $w_{h}$ man \& never-married woman & 7.8 & 7 & 6.6 \\
\hline divorced $w_{l}$ man \& never-married woman & 6.6 & 6 & 5.7 \\
\hline
\end{tabular}

Assuming excess supply of women, some women must be single in any given period, although not necessarily the same women. Because of the complementarity entailed by the consumption of public goods, the women with the lowest ex-post income cannot remarry. Who those women are depends on the redistribution regime. In general, it is possible that redistribution may also cause some men to refrain from marriage because of the potential loss of income that can arise following divorce. However, as reported in Table 3.A, under our choice of parameters, this does not happen.

Table 3.A: Marital History of Men

\begin{tabular}{|l|c|c|c|}
\hline Status & $\beta=.4$ & $\beta=.5$ & $\beta=.55$ \\
\hline Never Married & 0 & 0 & 0 \\
\hline Married and Never Divorced & .467 & .5 & .5 \\
\hline Divorced and Married ex-wife of a $w_{h}$ Man & .25 & .25 & .25 \\
\hline Divorced and Married ex-wife of a $w_{l}$ Man & 0 & .25 & .25 \\
\hline Divorced and Married Never-Married Women & .283 & 0 & 0 \\
\hline Divorced and Never Remarried & 0 & 0 & 0 \\
\hline Single and then Married & 0 & 0 & 0 \\
\hline
\end{tabular}

In contrast, some women are always single. Given a sex ratio of 1.3 women per each man, 23 percent of the women must be single every period. However, the proportion of women who never marry can be very small. As seen in Table 3.B, this happens when the husband's share of the family assets exceeds half, e.g., when $\beta=.4$. Then, divorced women are poorer than never married women and, therefore, divorced low-wage men in the second period will be matched with never-married women rather than with divorced women. 
Table 3.B: Marital History of Women

\begin{tabular}{|l|c|c|c|}
\hline Status & $\beta=.4$ & $\beta=.5$ & $\beta=.55$ \\
\hline Never Married & .017 & .3 & .3 \\
\hline Married to a $w_{h}$ Man and Never Divorced & .25 & .25 & .25 \\
\hline Married to a $w_{l}$ Man and Never Divorced & .217 & .25 & .25 \\
\hline Divorced a $w_{h}$ Man and Married a $w_{h}$ Man & .25 & .25 & .25 \\
\hline Divorced a $w_{h}$ Man and Married a $w_{l}$ Man & 0 & 0 & 0 \\
\hline Divorced a $w_{l}$ Man and Married a $w_{h}$ Man & 0 & 0 & 0 \\
\hline Divorced a $w_{l}$ Man and Married a $w_{l}$ Man & 0 & .25 & .25 \\
\hline Divorced a $w_{h}$ Man and Never Remarried & 0 & 0 & 0 \\
\hline Divorced a $w_{l}$ Man and Never Remarried & .283 & 0 & 0 \\
\hline Single then married a $w_{h}$ Man & 0 & 0 & 0 \\
\hline Single, then married a $w_{l}$ Man & .283 & 0 & 0 \\
\hline
\end{tabular}

We are now ready to discuss the divorce probabilities and utility payoffs associated with the different matching patterns displayed in Tables 4.A and 4.B. We begin by noting that first-period matches between any woman and a high-wage man dissolve with probability of 0.5 . The reason for this is that, if such a match dissolves, the husband will remain at the top of the male distribution and the wife will remain at the top of the female distribution and each spouse can remarry a clone of a former spouse. Hence, the current marriage and the potential remarriage are materially equivalent. Therefore, the current marriage will terminate if and only if the realized non-monetary quality of match $\theta$ is negative. On the other hand, we see in Table 2 that, following divorce, a low-wage husband becomes richer when $\beta=.4$, keeping 3.3 out of a total income of 6 in the current marriage. Walking away from the marriage, he can find a never-married woman in the remarriage market with whom he can produce an income of 6.6. This is why the marriage of a low-wage man and any woman can end in divorce even if $\theta>0$, provided that its value falls short of the material gain from divorce. Thus, despite the assumption of transferable utility, when remarriage is an option, the Becker-Coase Theorem fails to hold; redistribution can affect the divorce probability and the size of the "pie" that can be divided. 
Table 4.A: Divorce Probabilities and Utility Payoffs in the Three Regimes

\begin{tabular}{|l|}
\hline Outcomes \\
\hline Divorce Probability of $\left(w_{h}, w\right)$ marriage \\
\hline Divorce Probability of $\left(w_{l}, w\right)$ marriage \\
\hline 1st-period utility of married women $\left(w_{h}\right.$ husb. $)$ \\
\hline 1st-period utility of married women $\left(w_{l}\right.$ husb.) \\
\hline 1st-period utility of married $w_{h}$ men \\
\hline 1st-period utility of married $w_{l}$ men \\
\hline 2nd-per. utility of (re)married women $\left(w_{h}\right.$ hu. $)$ \\
\hline 2nd-per. utility of (re)married women $\left(w_{l}\right.$ hu. $)$ \\
\hline 2nd-period utility of (re)married $w_{h}$ man \\
\hline 2nd-period utility of (re)married $w_{l}$ men \\
\hline
\end{tabular}

\begin{tabular}{|c|}
\hline$\beta=.4$ \\
\hline .5 \\
\hline .565 \\
\hline 1.55 \\
\hline 2.51 \\
\hline 14.45 \\
\hline 6.48 \\
\hline 3.2 \\
\hline 2.4 \\
\hline 12.8 \\
\hline 6.6 \\
\hline
\end{tabular}

\begin{tabular}{|c|}
\hline$\beta=.5$ \\
\hline .5 \\
\hline .5 \\
\hline .75 \\
\hline 1.75 \\
\hline 15.25 \\
\hline 7.25 \\
\hline 4 \\
\hline 3 \\
\hline 12 \\
\hline 6 \\
\hline
\end{tabular}

\begin{tabular}{|c|}
\hline$\beta=.55$ \\
\hline .5 \\
\hline .5 \\
\hline .35 \\
\hline 1.45 \\
\hline 15.65 \\
\hline 7.55 \\
\hline 4.4 \\
\hline 3.3 \\
\hline 11.6 \\
\hline 5.7 \\
\hline
\end{tabular}

Table 4.B: Divorce Probabilities and Utility Payoffs in the Three Regimes

Outcomes

Expected lifetime utility of $w_{h}$ men w/o delay

Expected lifetime utility of $w_{h}$ men with delay

Expected lifetime utility of $w_{l}$ men w/o delay

Expected lifetime utility of $w_{l}$ men with delay

Expected lifetime utility of women ( $w_{h}$ husband)

Expected lifetime utility of women ( $w_{l}$ husband)

Expected lifetime utility of women with delay

$\beta=.4$
\begin{tabular}{|c|}
$\beta 27.25$ \\
\hline 16.29 \\
\hline 13.96 \\
\hline 9 \\
\hline 6 \\
\hline 6 \\
\hline 6 \\
\hline
\end{tabular}

$\beta=.55$
\begin{tabular}{|c|}
$\beta 27.25$ \\
\hline 18.9 \\
\hline 12.3 \\
\hline 11.25 \\
\hline 6 \\
\hline 6 \\
\hline 6 \\
\hline
\end{tabular}

When the redistributive impact of divorce laws is relatively small, but in favor of women for high-income households and against them in low-income ones, as is the case when $\beta=.4$, then all men and women prefer to participate in the marriage market without delay. However, because $r=1.3,0.3$ measure of women remain single and half of both high- and low-income marriages fail. Moreover, as shown in Table 2 , women who divorce low-income men end up having lower incomes than single women who do not marry in the first period. In the second period, .25 measure of divorced men with incomes of 4.8 and .283 measure of divorced men with incomes of 3.6 participate in the remarriage market. All of those men with high incomes marry divorced women of high-income marriages, who themselves end up with incomes of 3.2 , and all those men with the lower incomes marry never-married women with incomes of 3 . The 0.25 measure of divorced women of low-income marriages try to remarry but they cannot. And the excess supply of never-married, single women of measure .017 in the remarriage market, combined with divorced women of low-income marriages who end up having lower incomes than never married women (2.4 versus 
3), bounds from above the utility of women married to low-income men in the second period. Given that the divorced women of low-income marriages cannot remarry and remain single in the second period, .017 of single women of a total measure .3 will be never-married women and .25 will be divorcees of low-income men. The upper panel of Figure 1 depicts the equilibrium sorting patterns in the marriage market in both periods of Regime 1 .

When $\beta=.5$, household income is divided equally between the spouses in case of divorce; the so-called community property division rule. In this case all men and women still prefer to participate in the marriage market without delay. In the second period, .25 measure of divorced men with incomes of 4 and .25 measure of divorced men with incomes of 3 participate in the remarriage market. All of those men with high incomes marry divorced women with incomes of 4 and all those men with incomes of 3 either marry never-married women or divorced women of low-income marriages, both of whom have incomes of 3 . In sum, this regime is very much like the first one, except for the fact that the divorce laws are not as redistributive. Consequently, women of low-income marriages still end up with incomes of 3 upon divorce and any combination of remarriages versus first-time marriages among women is sustainable in the second period, provided that the measure of never-married, single women do not exceed .25 and the measure of those women of low-income marriages who remarry equals at most .25. The lower panel of Figure 1 depicts the equilibrium sorting patterns in the marriage market in both periods of Regime 2.

When the regime becomes even more favorable to women and the wives' share is raised from $\beta=.5$ to $\beta=.55$, we observe full policy neutrality. Neither men nor women delay marriage in both regimes and, despite the fact that $\beta$ is higher in Regime 3 than in Regime 2, the expected lifetime utilities of high- and low-income men as well as those of women are identical in both regimes. Nonetheless, the impact of higher $\beta$ in Regime 3 can be seen on the second-period allocations of women, which is higher. But those gains are fully offset by the lower first-period allocations women get in response to the change in $\beta$, leaving the expected lifetime utility levels of men and women unchanged in response to the change in divorce law.

Perhaps the most striking aspect of this example is that when a policy changes across regimes and becomes more favorable towards women social welfare declines according to the Pareto criterion. That is, low-wage men are increasingly worse off, while high-wage men and women are unaffected in terms of their expected life time utility. This surprising result illustrates that the marriage market responds to policy changes based on the whole income distribution of men and women and not directly 
with the income disparity between them within marriage or divorce (as is the case here). When women are in excess supply, married women cannot gain from more generous divorce settlements because they can be replaced by never-married women. Similarly, high-wage men are not affected by reductions in their share because, following divorce, they are ensured of marrying the ex-wives high-wage men. This in effect guarantees that policy changes do not lead to transfers away from such high-wage men. It is only the poor men who lose their ability to raise their household income by divorcing their wives and remarrying never-married women in the second period.

\section{Conclusion}

We have proposed a tractable assignment model with divorce and remarriage. Apart from making the assignment model more realistic, this extension has allowed us to address the impact of policy changes under different assumptions about commitment. When remarriage is not an option, we obtained a basic neutrality result which shows that any redistribution that the law imposes upon divorce can be undone within marriage, implying that, in the long run, changes in the laws governing divorce have no impact on the lifetime utility of the participants in the marriage market. In particular, if the policy improves the economic status of women upon divorce, then it must be the case that, while married, they receive a lower share of the monetary gains from marriage. Thus, an attempt to improve the status of women within marriage by transferring more resources to them in the case of divorce can be effective only in the short run for couples who were already married when the new policy is enacted. In this case, government intervention can have a different scope depending on the presence of prior commitments made at the time of marriage: only some of the precommitted couples, but all of the non-committed ones will choose to renegotiate their ex-ante contracts.

We have also shown that in general, neutrality fails to hold if remarriage is an option, although it may continue to hold under some strong assumptions. The new element introduced by remarriage is that redistribution of family assets upon divorce influences the income distributions of men and women that participate in the remarriage market. These changes can cause a reassignment of men to women with potentially important implications for marriage, divorce and the distribution of the gains from marriage.

It is important to compare the results of our paper with the results that would 
obtain in a search framework which include frictions. As shown by Mortensen (1988), such models can easily handle transitions across marital states, including divorce and remarriage, as well as learning about the quality of the match during marriage. However, in a search model, meetings occur randomly and are spaced over time. Therefore, when two agents meet and each of the matched partners can choose whether to marry or continue to search for an alternative mate, they are both aware of the cost of finding such an alternative. This creates a match-specific rent and some bargaining over the division of this rent takes place prior to marriage, with the continuation values of being single and maintaining the search serve as the natural threat points. In our model, there are neither frictions nor ex-ante rents as, irrespective of traits, each agent has a close substitute in the marriage market. This absence of rents allows us to pin down the sharing of marital gains based only on competitive forces.

In principle, one can embed our model in a more realistic search model with frictions. Then, our results will hold in the limit when meetings occur at high frequency and the discount factor is close to one (see Gale, 1986). Some of our results would hold even outside the limit. For instance, Garibaldi and Violante (2005) have shown that Lazear's result about the neutrality of severance payments also holds in a search economy. However, frictions can influence the patterns of assortative mating because agents are usually willing to compromise. For instance, the household production function $\zeta_{i j}=\left(w_{i}+w_{j}\right)^{2} / 4$ that we used in subsection 4.2 .1 ensures positive assortative matching without friction but not with frictions. In general, a stronger degree of complementarity is required in the presence of frictions (see Shimer and Smith, 2000). Still, two main messages would remain valid. The first is the differentiated effects of any reform on existing couples on the one hand, and couples yet to be formed on the other hand. An improvement in the wives' post divorce situation will favor women who are already married when the reform is implemented. However, couples who marry after the reform take the new law into account; to the extent that the nature of competition on the first marriage market is not changed by the reform (say, by attracting new potential spouses), lifetime utilities are likely to regress to their initial values, and (expected) gains in the second period will be paid for during the first. Secondly, while the reform is unlikely to have long-term effects on the allocation of welfare within the couple, it may well change the total surplus generated by marriage (it does even in our Becker-Coase framework when remarriage is taken into account, and frictions are likely to reinforce this effect). But then it has the paradoxical effect of either increasing both spouses' utilities, or decreasing both - quite the opposite of what one would expect. 
Finally, there are important features of the marriage relationship we did not address. In particular, we did not consider investments that influence the value of continued marriage or the outside options of the partners. When such considerations are added, the division of marital gains and the post-divorce settlement influence the size of marital surplus and the incentives to dissolve the marriage. Such a generalization is a natural extension that is subject for further work. Browning, Chiappori, Weiss (2003), Rasul (2006) and Rainer (2007) discuss investments in marriage but not in an equilibrium framework, which is yet to be done. Other possible extensions include risk aversion and different match valuations for the two spouses as in Chiappori and Weiss (2003) and limits on transferability as in Legros and Newman (2008). 


\section{References}

[1] Aiyagari, S., J. Greenwood, and N. Guner. (2000). "On the State of the Union," Journal of Political Economy, 108, 213-44.

[2] Barro, R. J. (1974), 'Are Government Bonds Net Wealth?', Journal of Political Economy, 82, 1095-1117.

[3] Becker, G. S. (1981). A Treatise on the Family, (MA: Harvard University Press).

[4] Becker, G. S. and K. M. Murphy. (2000). Social Economics, (MA: Harvard University Press).

[5] Bergstrom, T. (1989). "A Fresh Look at the Rotten Kid Theorem-and Other Household Mysteries", The Journal of Political Economy Vol. 97, No. 5, pp. 1138-1159.

[6] Bernheim, D. and K. Bagwell. (1988). "Is Everything Neutral?," Journal of Political Economy, 96 (2), 308-38.

[7] Bourguignon, F. and P. Chiappori. (1994). "The Collective Approach to Household Behavior," in R. Blundell, I. Preston, and I. Walker eds., The Measurement of Household Welfare, (Cambridge, U.K.: Cambridge University Press).

[8] Browning, M., F. Bourguignon, P. A. Chiappori, and V. Lechene. (1994). "Income and Outcomes: A Structural Model of Intrahousehold Allocation," Journal of Political Economy, 102 (6), 1067-96.

[9] Browning, M., P. A. Chiappori, and Y. Weiss. (2003). "A Simple Matching Model of the Marriage Market," University of Chicago, unpublished manuscript.

[10] Browning, M., P. A. Chiappori, and Y. Weiss. (in progress). Family Economics, (Cambridge: Cambridge University Press).

[11] Burdett, K., R. Imai, and R. Wright (2004). "Unstable Relationships," Frontiers of Macroeconomics, Volume 1, Article 1, http:// www.bepress.com /bejm/frontiers/vol1/iss1 /art1.

[12] Census Bureau. (1992). Current Population Reports: Marriage, Divorce, and Remarriage in the 1990s, (Washington, D.C.: U.S. Department of Commerce).

[13] Chiappori, P. A. (1988). "Rational Household Labor Supply," Econometrica, 56, 63-90. 
[14] Chiappori, P. A. (1992). "Collective Labor Supply and Welfare," Journal of Political Economy, 100 (3), 437-67.

[15] Chiappori, P. A., B. Fortin, and G. Lacroix. (2002). "Marriage Market, Divorce Legislation, and Household Labor Supply," Journal of Political Economy, $110(1), 37-72$.

[16] Chiappori, P. and Y. Weiss. (2003). "Marriage Contract and Divorce: A General Equilibrium Approach," Unpublished Manuscript, Tel Aviv University.

[17] Chiappori, P. and Y. Weiss. (2006). "Divorce, Remarriage and Welfare: A General Equilibrium Approach," Journal of the European Economic Association, $4,415-426$.

[18] Chiappori, P. and Y. Weiss. (2007). "Divorce, Remarriage and Child Support," Journal of Labor Economics, 25, 37-74.

[19] Chiappori, P. A. M. Iyigun and Y. Weiss. (forthcoming). "Investment in Schooling and the Marriage Market," American Economic Review, 2009.

[20] Chiappori, P. A. M. Iyigun and Y. Weiss. (2007). "Public Goods, Transferable Utility and Divorce Laws," IZA Working Paper No: 2646, March.

[21] Clark, S. (1999), "Law, Property, and Marital Dissolution," The Economic Journal, 109, c41-c54.

[22] Diamond, P. and E. Maskin. (1979). "An Equilibrium Analysis of Search and Breach of Contract, I: Steady States," Bell Journal of Economics, 10, 282-316.

[23] Duflo, E. (2003). "Grandmothers and Granddaughters: Old Age Pension and Intra-Household Allocation in South Africa," World Bank Economic Review, 17 (1) $1-25$.

[24] Friedberg, L. (1998). "Did Unilateral Divorce Raise Divorce Rates: Evidence from Panel Data," American Economic Review, 88 (3), June, 608-27.

[25] Gale, D. and L. Shapley. (1962). "College Admission and the Stability of Marriage," American Mathematical Monthly, 69: 9-15.

[26] Gale, D. (1986). "Bargaining and Competition, Parts I and II," Econometrica, $54,785-818$.

[27] Garibaldi, P. and G. Violante (2005). "The Employment Effects of Severance Payments with Wage Rididities," The Economic Journal, 115, 799-382. 
[28] Goldin, C. (1990). Understanding the Gender Gap: An Economic History of American Women, (New York: Oxford University Press).

[29] Iyigun, M. and R. P. Walsh. (2007a). "Building the Family Nest: Pre-Marital Investments, Marriage Markets and Spousal Allocations," Review of Economic Studies, 74:2, April, 507-35.

[30] Iyigun, M. and R. Walsh. (2007b). "Endogenous Gender Power, Labor Supply, and the Quantity-Quality Tradeoff," Journal of Development Economics, 82:1, January, 138-55.

[31] Kapan, T. (2008). Ph. D. Dissertation manuscript, Columbia University, mimeo, in progress.

[32] Kocherlakota, N. and L. Pistaferri ( 2008). "Household Heterogeneity and Asset Trade: Resolving the Equity Premium Puzzle in Three Countries" Unpublished Manuscript, University of Minnesota.

[33] Lazear, E. (2000). "Job Security and Employment," The Quarterly Journal of Economics, 105, 699-726.

[34] Legros, P. and A. Newman (2007). "Beauty is a Beast, Frog is a Prince: Assorrtative Matching with Nontrasferabilities," Econometrica, 75, 1073-1102.

[35] Ligon, E., Thomas, J. and T. Worrall (2002). "Inforamal Insurance Arrangements with Iimited Commitment: Theory and Evidence from Village Economies," Review of Economic Studies, 69, 209-244.

[36] Lundberg, S. and R. A. Pollak. (1993). "Separate Spheres Bargaining and the Marriage Market," Journal of Political Economy, 101 (6), 988-1010.

[37] Manser, M. and M. Brown. (1980). "Marriage and Household DecisionMaking: A Bargaining Analysis," International Economic Review, 21, February, $31-44$.

[38] Masters, A. (2005). "Marriage, Commitment and Divorce in a Matching Model with Differential Aging," unpublished manuscript, SUNY Albany, May.

[39] Matouschek, N. and I. Rasul. (2008). "The Economics of the Marriage Contract: Theories and Evidence," Journal of Law \& Economics, 51, 59-110.

[40] Mazzocco, M. "Household Intertemporal Behaviour: A Collective Characterization and a Test of Commitment," Review of Economic Studies, 74, 857-895. 
[41] McElroy, M. B. and M. J. Horney. (1981). "Nash-Bargained Decisions: Towards a Generalization of the Theory of Demand," International Economic Review, 22, June, 333-49.

[42] Mortensen, D. (1988). "Wages, Separations and Job Tenure: On the Job Specific Training or Matching?," Journal of Labor Economics, 6:4, October.

[43] Oreffice, S. (2007). "Did the Legalization of Abortion Increase Women's Household Bargaining Power? Evidence from Labor Supply." Review of Economics of the Household, 5, 181-207.

[44] Peters, L. (1986). "Marriage and Divorce: Informational Constraints and Private Contracting," American Economic Review, 76 (3), June, 437-54.

[45] Rainer, H. (2007). "Should We Write Prenuptial Contracts?" European Economic Review, 51, 337-363.

[46] Rasul, I. (2005). "Marriage Markets and Divorce Laws," Journal of Law, Economics, and Organization, 22, 30-69.

[47] Rasul, I. (2006). "The Economics of Child Custody," Economica, 73, 1-25.

[48] Roth, A. and M. Sotomayor. (1990). Two Sided Matching: A Study in GameTheoretic Modeling and Analysis, (Cambridge: Cambridge University Press).

[49] Rubacalva, L., Teruel, G. and D. Thomas (2008). "Investments, Time Preferences and Public Transfers Paid to Women", mimeo UCLA.

[50] Samuelson, P. (1956). "Social Indifference Curves," Quarterly Journal of Economics, 70 (1), 1-22.

[51] Sen, A. (1983). "Economics and the Family," Asian Development Review, 1, 14-26.

[52] Shimer, R. and L. Smith. (2000). "Assortative Matching and Search," Econometrica, 68: 343-69.

[53] Weiss, Y. (1977). "The Formation and Dissultion of Families: Why Marry? Who Marries Whom? and What Happens upon Divorce," in Rosenzwieg, M. and O. Stark (editors) Handbook of Population and Family Economics, Amssterdam: Elsevier.

[54] Wolfers, J. (2006). "Did Unilateral Divorce Raise Divorce Rates? A Reconciliation and New Results," American Economic Review, 96 (5), December, 1802-20. 
Figure 1: Spousal Assignment Patterns in the Two Periods
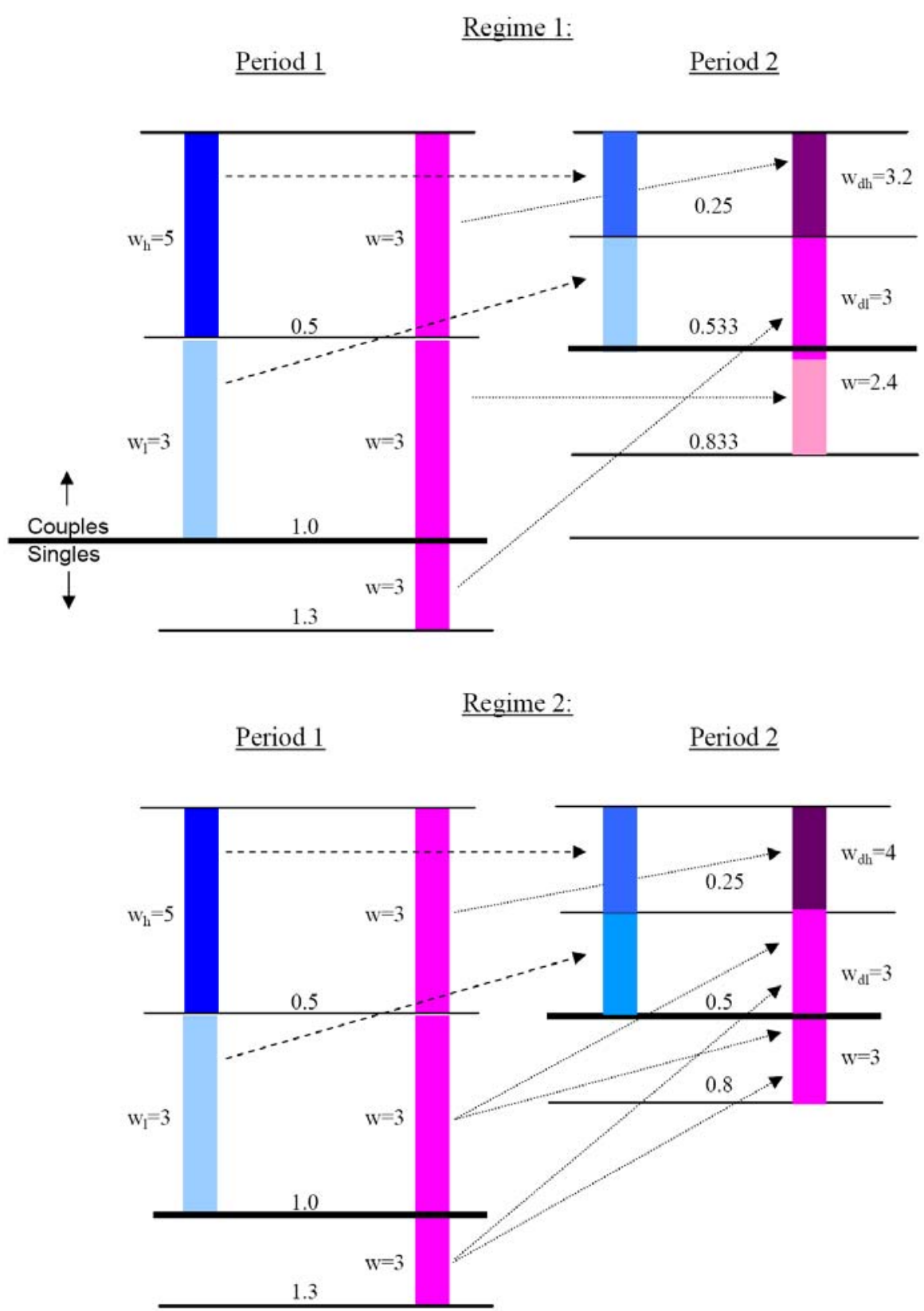


\section{A Assortative matching}

It is sufficient to show that the expected surplus of a marriage, given by $\tilde{S}(t)=$ $S(t)-2 t$, is increasing and convex in $t$, where $t=y+z$.

$$
\begin{aligned}
\tilde{S}(t) & =\eta(t)+2 \bar{\theta}+(1-\alpha(t))(\eta(t)+2 E[\theta \mid \theta \geq \hat{\theta}(t)])+\alpha(t) t-2 t \\
& =\eta(t)+2 \bar{\theta}+\int_{\hat{\theta}}^{\infty}(\eta(t)+2 \theta) f(\theta) d \theta+t \int_{-\infty}^{\hat{\theta}} f(\theta) d \theta-2 t
\end{aligned}
$$

with

$$
\hat{\theta}(t)=-\frac{1}{2}(\eta(t)-t) .
$$

Recall that $\eta(t)$ is strictly convex and $\eta^{\prime}(t)>1$. Therefore,

$$
\begin{aligned}
\tilde{S}^{\prime}(t) & =\eta^{\prime}(t)\left(1+\int_{\hat{\theta}}^{\infty} f(\theta) d \theta\right)+\int_{-\infty}^{\hat{\theta}} f(\theta) d \theta+f(\hat{\theta})[-\eta(t)-2 \hat{\theta}+t] \hat{\theta}^{\prime}(t)-2 \\
& =\eta^{\prime}(t)+\eta^{\prime}(t) \int_{\hat{\theta}}^{\infty} f(\theta) d \theta+\int_{-\infty}^{\hat{\theta}} f(\theta) d \theta-2>0 .
\end{aligned}
$$

and

$$
\begin{aligned}
\tilde{S}^{\prime \prime}(t) & =\eta^{\prime \prime}(t)\left(1+\int_{\hat{\theta}}^{\infty} f(\theta) d \theta\right)+f(\hat{\theta})\left[-\eta^{\prime}(t)+1\right] \hat{\theta}^{\prime}(t) \\
& =\eta^{\prime \prime}(t)\left(1+\int_{\hat{\theta}}^{\infty} f(\theta) d \theta\right)+f(\hat{\theta}) \frac{\left[\eta^{\prime}(t)+1\right]^{2}}{2}>0 .
\end{aligned}
$$

Hence, $S(t)$ is convex in $t$, implying that $z$ and $y$ are complements. 